\title{
CoPPER-BEARING (PARAÍBA-TYPE) TOURMALINE FROM MOZAMBIQUE
}

\author{
Brendan M. Laurs, J. C. (Hanco) Zwaan, Christopher M. Breeding, William B. (Skip) Simmons, \\ Donna Beaton, Kenneth F. Rijsdijk, Riccardo Befi, and Alexander U. Falster
}

\begin{abstract}
Copper-bearing tourmaline from Mozambique was first recovered in 2001, but its Cu content was not recognized until 2003, and it was not widely sold with its Mozambique origin disclosed until 2005. It has been mined from alluvial deposits in an approximately $3 \mathrm{~km}^{2}$ area near Mavuco in the eastern portion of the Alto Ligonha pegmatite district. Most of the production has come from artisanal mining, with hand tools used to remove up to $5 \mathrm{~m}$ of overburden to reach the tourmalinebearing layer. The stones exhibit a wide range of colors, typically pink to purple, violet to blue, and blue to green or yellowish green. Heat treatment of all but the green to yellowish green stones typically produces Paraíba-like blue-to-green hues by reducing absorption at $\sim 520 \mathrm{~nm}$ caused by the presence of $\mathrm{Mn}^{3+}$. The gemological properties are typical for Cu-bearing tourmaline (including material from Brazil and Nigeria); the most common inclusions consist of partially healed fractures and elongate hollow tubes. With the exception of some green to yellow-green stones, the tourmalines examined have relatively low $\mathrm{Cu}$ contents and very low amounts of Fe and Ti. Mechanized mining is expected to increase production from this region in the near future.
\end{abstract}

opper-bearing tourmaline, in bright blueto-green hues, is one of the most soughtafter colored stones in the gem market. Soon after its discovery in Brazil's Paraíba State in the late 1980s (Koivula and Kammerling, 1989), the material gained notoriety for its beautiful "neon" colors, and prices escalated rapidly. Additional deposits were found in Paraíba and in neighboring Rio Grande do Norte State during the 1990s (Shigley et al., 2001). Then, in 2001, Cu-bearing tourmaline was discovered in Nigeria (Smith et al., 2001). At least three Nigerian localities were subsequently recognized (Furuya and Furuya, 2007; Breeding et al., 2007). The newest source of Cubearing tourmaline is Mozambique, which was first described in 2004 (Wentzell, 2004). Eventually, the gem trade learned that the source was the Mavuco (or Chalaua) area in the Alto Ligonha pegmatite district. It is probably the world's largest known deposit of Cu-bearing tourmaline, and the "neon" blue and green shown by the finest stones closely resembles the most sought-after material from Paraíba (figure 1). Mavuco actually produces a wide variety of colors, including unusual deep purple amethyst-like hues and steely violetish blues (figure 2). Of the several hundred kilograms of tourmaline rough mined to date in the Mavuco area, about 10\% show blue-to-green Paraíba-like colors without heat treatment (M. Konate, pers. comm., 2007).

The Cu-bearing tourmaline from this area may have been sold initially as Brazilian material (in various countries around the world, including Brazil), since the Mozambique origin was not correctly and

See end of article for About the Authors and Acknowledgments.

Gems \& Gemology, Vol. 44, No. 1, pp. 4-30.

(C) 2008 Gemological Institute of America 


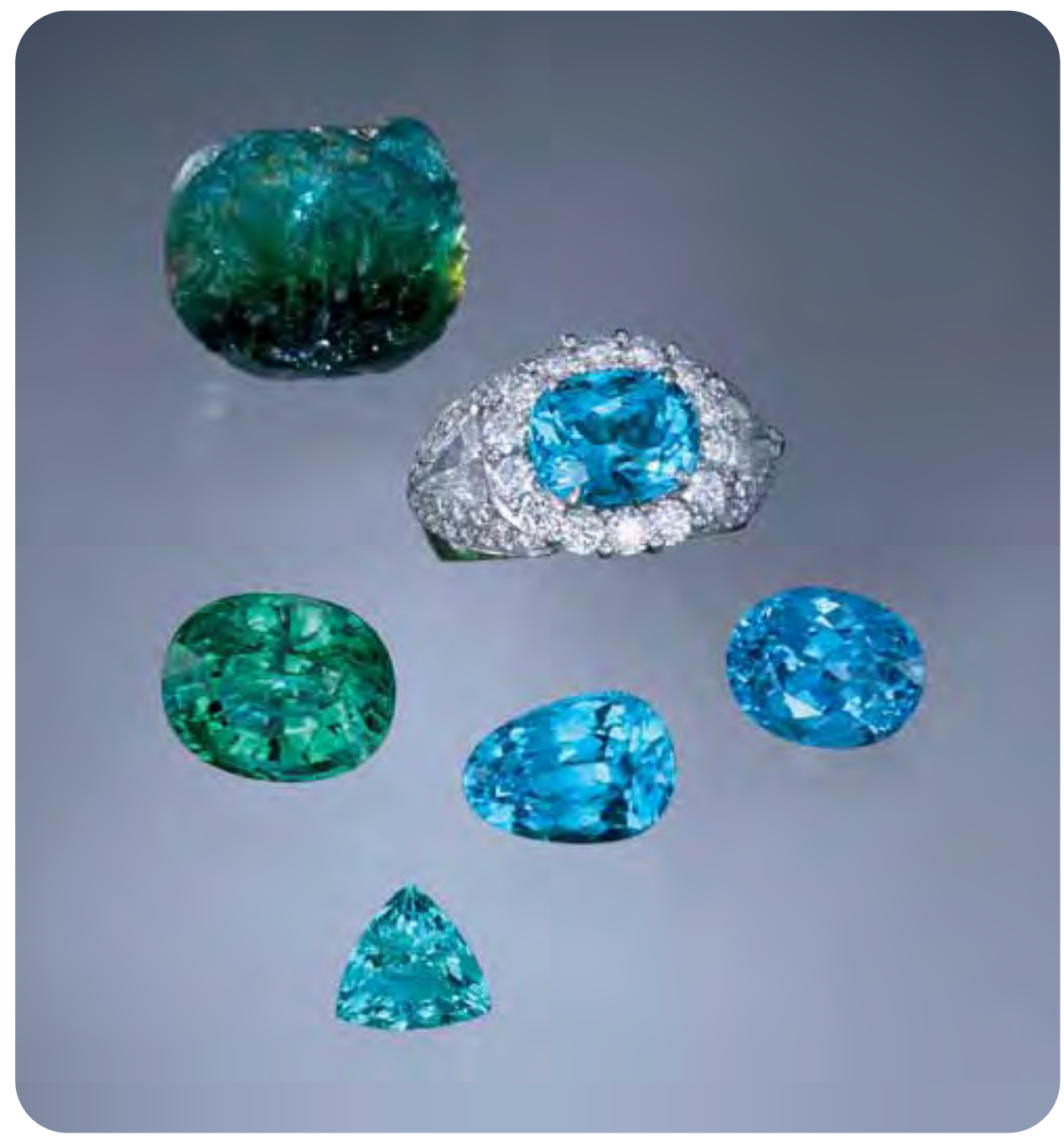

Figure 1. Copper-bearing tourmal ine from

Mozambique is found as alluvial pebbles (upper left, approximately $11 \mathrm{~g}$ ) and is faceted into a variety of bright colors, including the most desirable "neon" blue and green. The center stonein the ring weighs approximately $5 \mathrm{ct}$, and the other faceted tourmalines weigh 6.73-15.77 ct; the blue teardrop in the center and the stonein the ring have been heat treated. Ring courtesy of The Collector Fine Jewel ry, Fallbrook, California, and loose stones courtesy of Barker \& Co. and Pala International; photo @ Harold and Erica Van Pelt.

widely marketed until the September 2005 Hong Kong International Jewelry Fair (A bduriyim and Kitawaki, 2005; Abduriyim et al., 2006). Although most deal ers agree that the M ozambique material's blue-to-green col ors are typical ly somewhat less saturated than those of its Brazilian counterpart, the lower price and greater availability have hel ped fuel this tourmaline's continued popularity. The larger number of eye-clean stones in the 20-60 ct range has al so created excitement ("M ozambique Parai ba tourmaline hot in Tucson," 2007; Wise, 2007). The largest clean faceted "neon" blue Paraíba-type stone from Mozambique known to these authors weighs 88.07 ct (figure 3).

$M$ avuco lies on the eastern side of the Alto Ligonha pegmatite district, which is well known for producing superb gem material and/or specimens of tourmaline, beryl, topaz, and other species (e.g., Bettencourt Dias and Wilson, 2000). Most of the Alto Ligonha pegmatites are located west of Ligonha
River, whereas the Cu-bearing tourmaline deposit is on the east side. Even further east, the M onapo$\mathrm{N}$ acala area is another source of pegmatite minerals,

Figure 2. Ranging from 10.66 to $16.50 \mathrm{ct}$, these stones show some of the vivid colors seen in Cu-bearing tourmaline from Mozambique. All are reportedly unheated. Courtesy of Barker \& Co. and Pala International; photo by Robert Weldon.

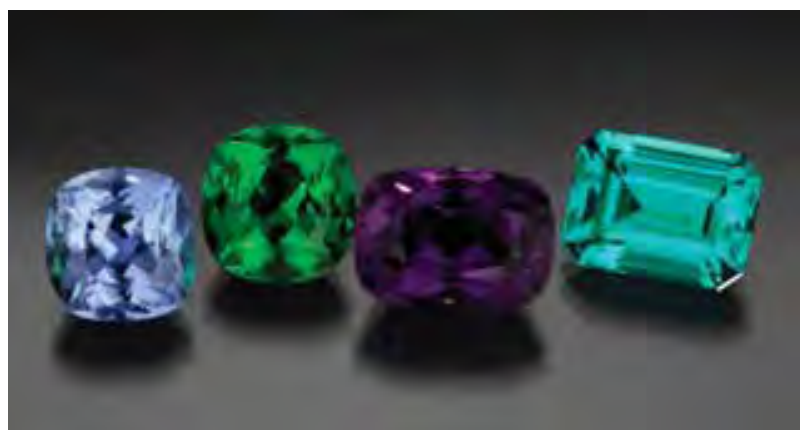




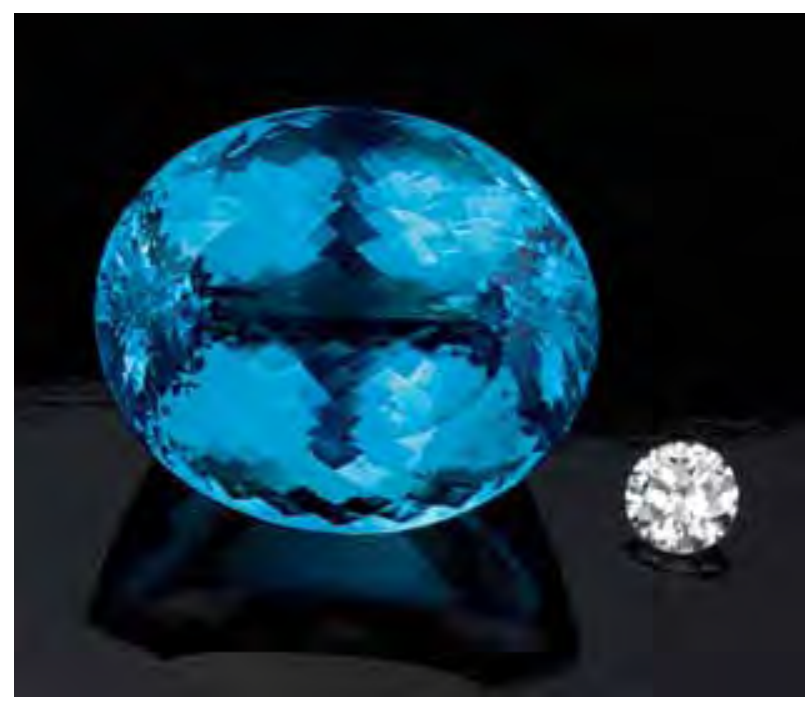

Figure 3. At $88.07 \mathrm{ct}$, this is the largest faceted "neon" blue Paraíba-type tourmaline from M ozambique that the authors have seen (heated stone, courtesy of Mozambique Gems). A 1 ct diamond is shown for scale (courtesy of GIA). Photo by Robert Weldon.

including alluvial tourmal ine (Correia $\mathrm{N}$ eves et al., 1972; Petsch, 1985), but no Cu-bearing material is known from there.

To date, Cu-bearing tourmaline from M ozambique has been described most thoroughly by Abduriyim et al. (2006), Milisenda et al. (2006), Furuya and Furuya (2007), and Rondeau and Delaunay (2007). All of these authors have presented chemical analyses, and some illustrated how traceelement chemistry can be used to separate the M ozambique tourmalines from their Brazilian and $\mathrm{N}$ igerian counterparts. The present article introduces additional chemical data for the M ozambique material and characterizes the gemological properties in detail. Information on the geology and mining was gathered by authors BML and JCZ during a five-day visit to the Mavuco area in August-September 2007. These authors were guided by Mozambique Gems Ltd., which filed the first mining claim in the area for the Paraíba-type tourmaline and has been preparing for a major mechanized operation.

\section{HISTORY}

Tourmaline, in a variety of vivid colors, was first recovered from the Mavuco area in 2001 by local farmers (M. Konate, pers. comm., 2007). In 2003, M oses Konate (current owner of Mozambique Gems) sold a parcel of this tourmaline in the United States, and was subsequently informed that it con- tained traces of copper. As with Paraíba-type tourmaline from other localities, some of the stones turned bright blue to blue-green when heated to moderate temperatures. M ozambique then joined Brazil and Nigeria as the world's only known sources of this attractive tourmaline.

Soon, about 300 local people were working a small area for the tourmaline. In July 2004, M r. Konate filed a 300-hectare claim, and eventually others surrounded this concession with a series of larger claims. During the ensuing mining rush, Mr. Konate secured his claim from illegal mining and assembled four overseas partners to help finance a mechanized mining operation. In preparation for this operation, the group secured the permits needed for mining, performed mapping and exploration, and undertook an environmental impact study. They have also helped the local community by providing employment, sharing electricity from their generator, and assisting with the construction of a medical clinic in Mavuco.

Prior to the discovery of the tourmaline, fine crystals of aquamarine and quartz were recovered from miarolitic cavities in nearby pegmatites during the mid-1980s to the late 1990s. Some of this mining was actually done on the northwest portion of M ozambique Gems' present claim, but the tourmaline was not recognized at the time because the al luvial layer that hosts it was buried by up to several meters of overburden.

\section{LOCATION AND ACCESS}

The mining area is located in northeastern M ozambique, in N ampula Province, adjacent to the village of Mavuco (figure 4). M easured in a straight line, Mavuco is located approximately $95 \mathrm{~km}$ southsouthwest of the city of Nampula, from which the mining area can be reached in a sturdy vehicle in $2 \frac{1}{1} 2-3$ hours. The route follows a paved road $80 \mathrm{~km}$ to the village of Murrupula, and then $86 \mathrm{~km}$ of dirt road to a crossing located nearly hal fway between the villages of Iulùti (or Lulùti) and Chalaua. From the crossing, a dirt track proceeds a few more kilometers to the mining area.

The Mavuco region marks a gradual transition from the lower coastal plains in the southeast toward the higher plateaus in the northwest. The mining area is rather flat, but a few kilometers to the south are a pair of prominent granite monoliths (inselbergs or kopjes) with an altitude of approximately $600 \mathrm{~m}$ that are collectively known as $\mathrm{Mt}$. Muli. Mavuco means lakes, in reference to low 


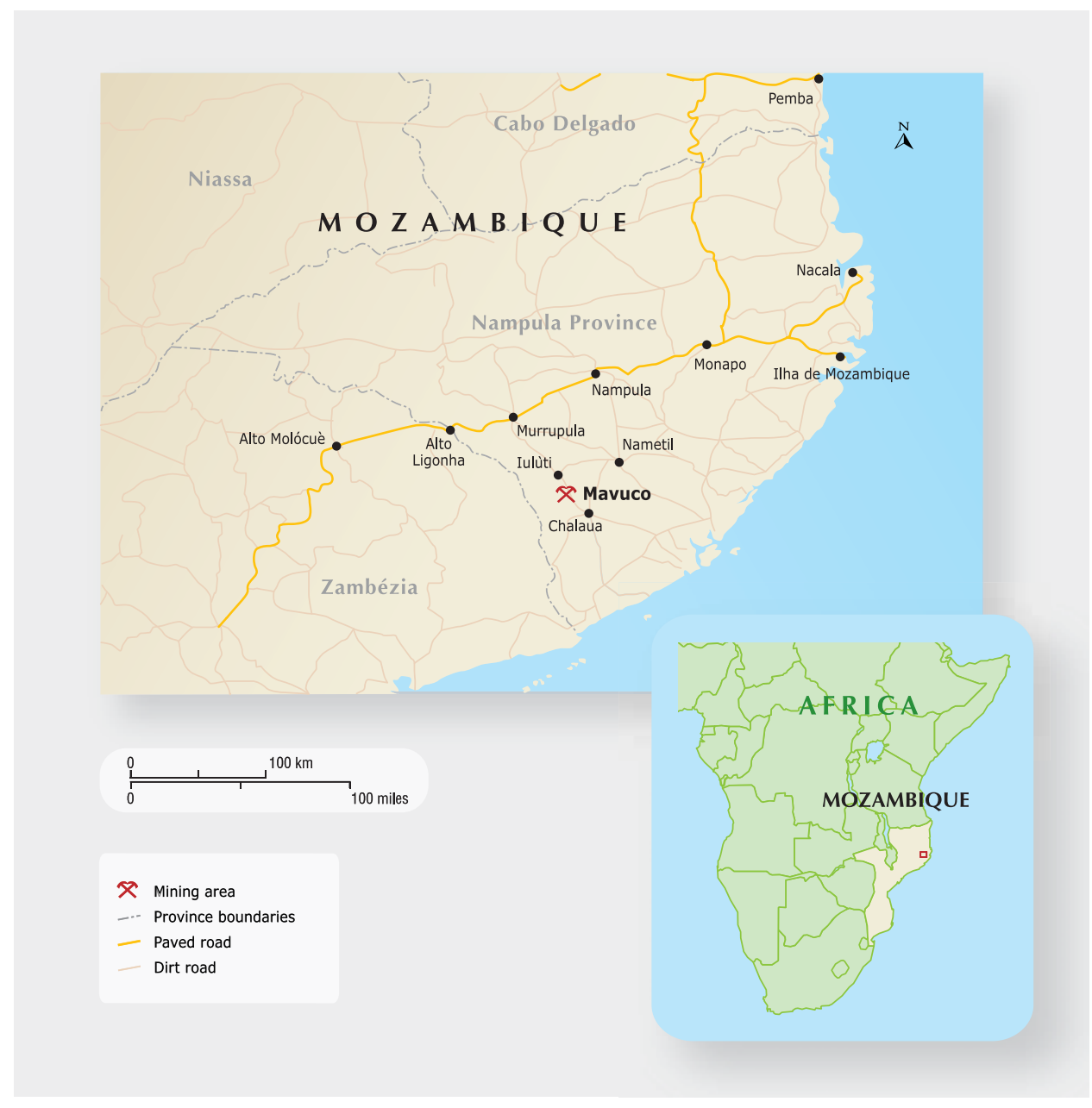

Figure 4. Cu-bearing tourmalines are found in northeastern Mozambique, in Nampula Province, near the village of Mavuco. From Nampula, Mavuco can be reached via Murrupula.

areas near Mt. Muli that fill with water during the rainy season. For much of the year, though, water must be carried from seasonal streams to Mavuco by local entrepreneurs on bicycles.

Mavuco has a tropical humid climate, with a dry period in winter. The average temperature in $\mathrm{N}$ ampula Province varies from $-23^{\circ} \mathrm{C}\left(73^{\circ} \mathrm{F}\right)$ in A pril to $-28^{\circ} \mathrm{C}\left(82^{\circ} \mathrm{F}\right)$ in October-December; average rainfall varies from $15-25 \mathrm{~mm}$ (an inch or less) in the period May-September, to 250-260 mm (about 10 inches) in January-February (Slater, 2006). The vegetation consists of open savanna, and farmers use much of the land around the mining area to grow crops such as cassava, maize, beans, cashew nuts, and various fruits.

\section{GEOLOGY}

The basement rocks in the Mavuco area form part of the Mozambique Belt (1100-800 million years old [Ma]), which extends from the Mediterranean Sea down to central Mozambique (Lächelt, 2004).
This orogenic belt hosts rich gem and mineral weal th over a large area from M ozambique through Tanzania and Kenya (Bettencourt Dias and Wilson, 2000). In northern M ozambique, the basement consists primarily of strongly metamorphosed gneisses (migmatites) that were mainly deformed during the Pan-African tectonic event (800-550 Ma). During the period 600-410 $\mathrm{Ma}$, these rocks were intruded by granitoids and rare-element granitic pegmatites (e.g., Pinna et al., 1993; Lächelt, 2004; figure 5). Most of the pegmatites were emplaced within approximately $200 \mathrm{~km}$ of Alto Ligonha. Since the 1930s, they have been mined for a variety of commodities, including rare metals ( $\mathrm{Li}, \mathrm{Be}, \mathrm{N} \mathrm{b}$, and $\mathrm{Ta}$ ), industrial minerals (quartz, mica, fel dspar, and clay), and gems such as tourmaline and beryl (Bettencourt Dias and Wilson, 2000; Lächelt, 2004).

The Mavuco area is tropically weathered and mostly covered by deep lateritic soil. Recent regionalscal e geologic mapping, carried out by M ozambique's National Directorate of Geology and supported by the World Bank, shows that the principal rock types 


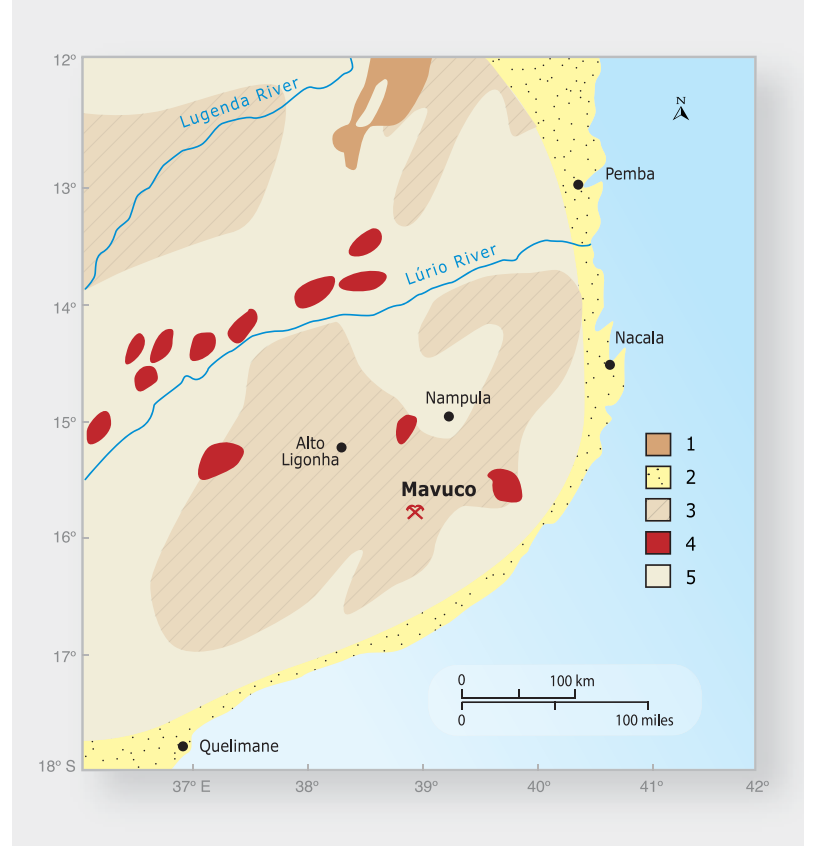

consist of various types of gneiss (mapped as the N antira/M etil Group by Pinna et al., 1986), as well as the granites of Mt. Muli and Mt. Iulùti (figure 6).
Figure 5. The area where the $\mathrm{Cu}$-bearing tourmalines are found lies on the eastern side of the well-known Alto Ligonha pegmatite district. This geologic sketch map shows the principal tectonic-geologic units: (1) rift of the East African Rift System; (2) Mesozoic and Cenozoic sedimentary rocks; (3) pegmatite fields; (4) Pan-African intrusions; (5) Mozambican areas, part of the Mozambique Belt and mostly remetamorphosed during the Pan-A frican tectonic event. Modified after Lächelt (2004).

Simple granitic pegmatites locally crosscut the basement rocks and form quartz-rich outcrops where the host gneisses are exposed at the surface (particularly common in the northwest portion of Mozambique Gems' claim). They consist of milky, rose, and/or clear, transparent quartz, pink Kfeldspar, and black tourmaline, with rare micas and sometimes beryl. Although these pegmatites are found quite close to the area mined for Cu-bearing tourmaline, they are not the source of this material, as expected from their Li-poor composition.

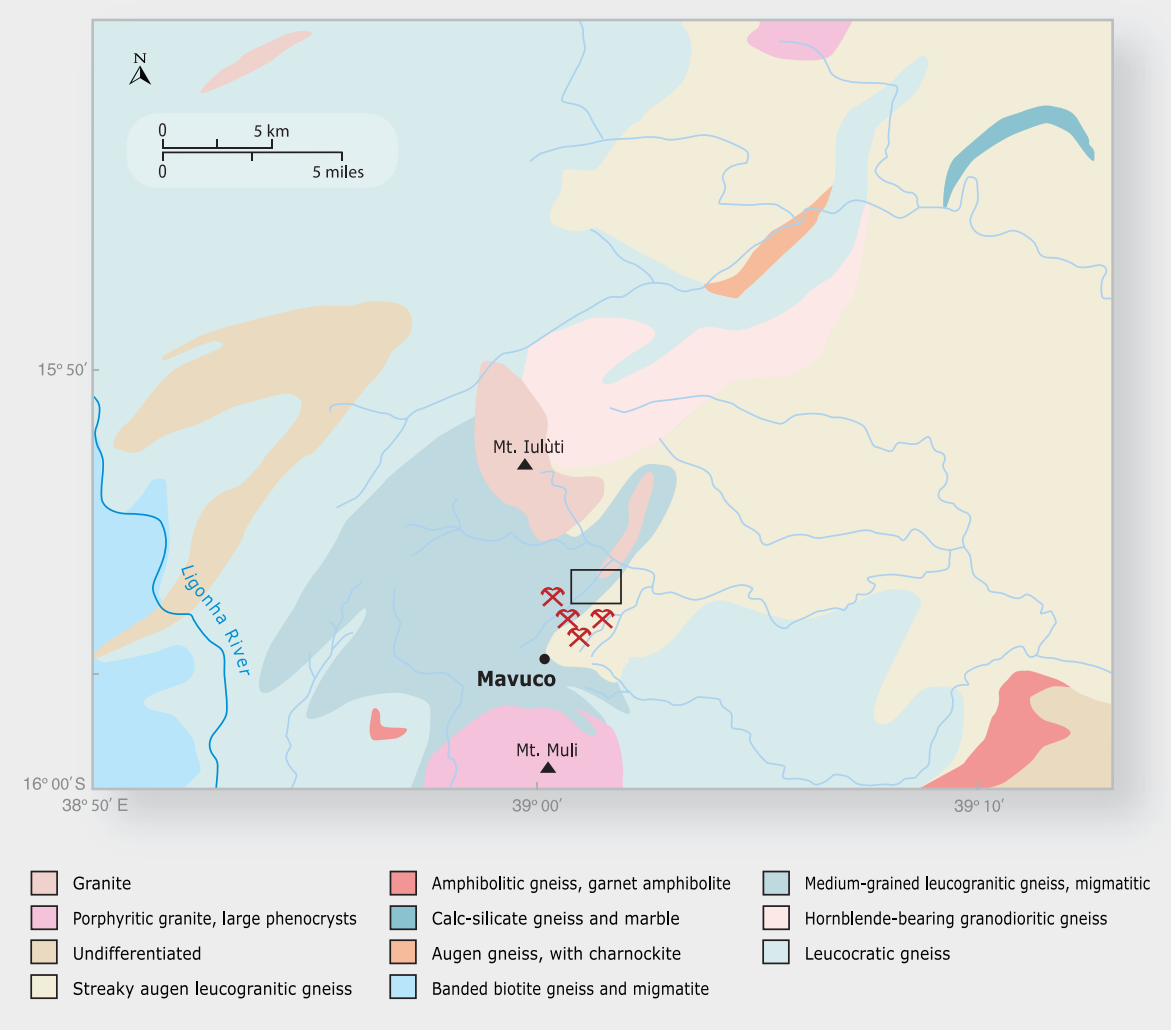

Figure 6. The inferred basement rocks in the Mavuco area are shown on this geol ogic map. The map is part of an asyet unpublished regional map that was recently compiled by Mozambique's National Directorate of Geology as part of an ongoing project financed by the World Bank. The Cubearing tourmaline deposit is situated approximately between two granitic massifs, Mt. Muli and Mt. Iulùti. The rectangle shows the mining concession of Mozambique Gems Ltd. 


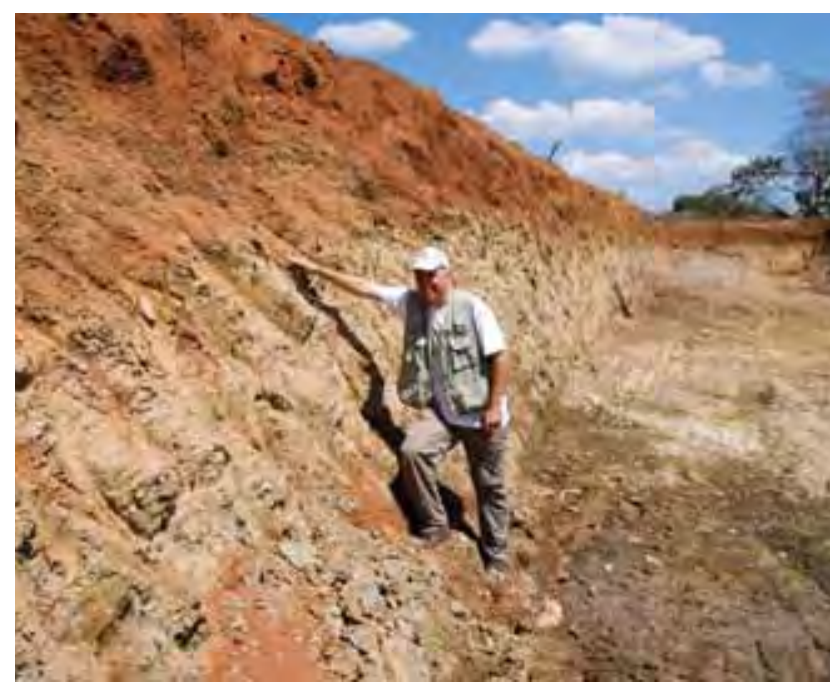

Figure 7. This large pit on the Mozambique Gems claim shows a good cross-section of the geology of the deposit (left; photo by B. M. Laurs). The tourmalines are found in a light reddish brown quartz-rich gravel

layer on top of light tan weathered bedrock, and underneath a top layer of red-brown clayey soil. The

gravel layer can be found between $0.5 \mathrm{~m}$ and $5 \mathrm{~m}$ below the surface in the Mavuco area. The thickness of the tourmaline-bearing gravel layer is indicated by the men in the image on the right (photo by J. C. Zwaan).

The Cu-bearing tourmaline has only been found as waterworn pebbles in secondary deposits. The tourmaline-bearing layer (pal eoplacer) rests on top of weathered biotite gneiss bedrock, and itsel $f$ is covered by a red-brown to black tropically weathered horizon (laterite; figure 7). The laterite varies in thickness from approximately $0.5 \mathrm{~m}$ near seasonal streams to typically 3-5 $\mathrm{m}$. The tourmal ine-bearing gravel layer is generally between several centimeters and $1 \mathrm{~m}$ thick and ranges from light gray to redbrown. The latter color is due to the weathering of iron-bearing materials, which has locally stained the clasts and interstitial clays within the gem-bearing layer. Available exposures of this layer showed that it is flat-lying. It is predominantly comprised of fine- to medium-sized gravels $(0.2-30 \mathrm{~mm})$ and local pebbles (typically $40-70 \mathrm{~mm}$ ). The gravels are clast-supported, showing an open-worked matrix (i.e., containing many empty spaces, and in places no matrix at all). The individual pebbles are typical ly coated with a red clayey silt (figure 8). The gravels consist mainly of milky to transparent quartz; less common are partially weathered feldspar and black or colored tourmaline. The gravels are dominated by subangular clasts ( $>90 \%)$, with the bal ance subrounded to rounded. The colored tourmalines

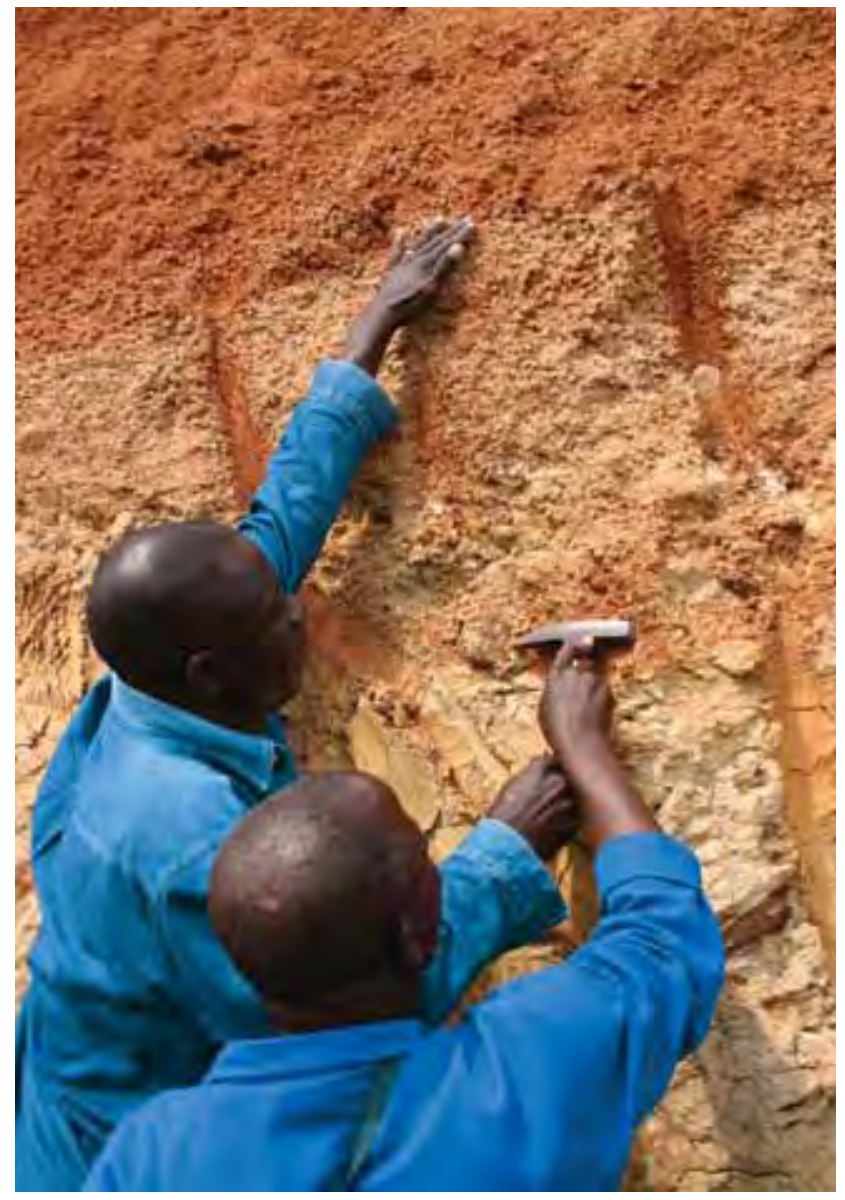

fall into the latter category, although some pieces we encountered still showed traces of striations on the prism surfaces (figure 9).

Figure 8. The tourmaline-bearing layer is a quartzrich, clast-supported gravel. Many of the clasts are angular, such as the larger $(5 \mathrm{~cm})$ quartz pebble toward the right in this image. Photo by J. C. Zwaan.

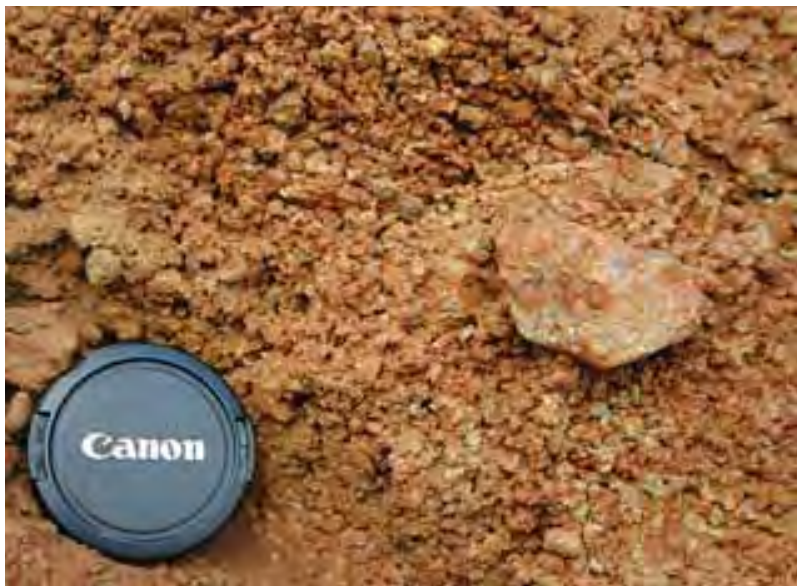




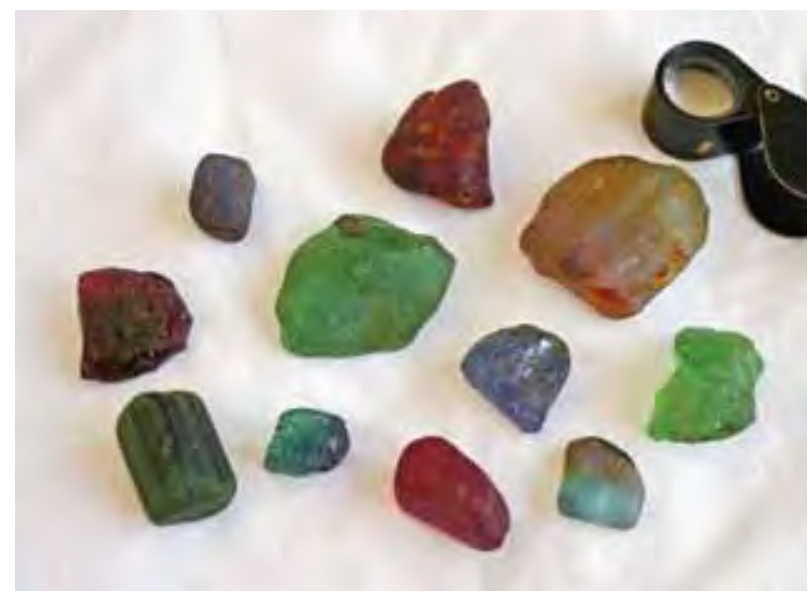

Figure 9. Copper-bearing tourmalines from Mozambique are found as waterworn pebbles that only rarely show traces of striations on the prism surfaces. This selection of larger rough-some with evidence of striations-was taken from a $1 \mathrm{~kg}$ parcel of unheated Cu-bearing tourmalineseen in Nampula. Photo by J. C. Zwaan.

\section{MINING}

The Cu-bearing tourmal ine recovered thus far comes from an approximately $3 \mathrm{~km}^{2}$ area near Mavuco (figure 10). Informal diggers have done most of the mining on the south and east sides of Mozambique Gems' 300-hectare mining concession. The area that has been explored/mined for the tourmaline is roughly bounded by coordinates $15^{\circ} 54^{\prime}-15^{\circ} 57^{\prime} \mathrm{S}$ and $39^{\circ} 00^{\prime}-39^{\circ} 03^{\prime} \mathrm{E}$, at elevations between $150 \mathrm{~m}$ (near seasonal streams) and $200 \mathrm{~m}$ above sea level. The extent of the tourmaline-bearing horizon has not yet been determined, although during the visit by BML and JCZ miners reported encountering only black tourmaline on some edges of the mined area, leading them to search elsewhere.

The artisanal miners use picks and shovels to dig through the hard laterite in search of the gem-bearing layer (figure 11). They remove the tourmaline pebbles by hand while digging through the gravels with a pick (figure 12). Although many gems are probably overlooked in the process, water for washing the gravel is scarce or unavai lable to the artisanal miners during most of the year, and the material is cemented by clay so dry screening is not feasible. Most of the rough material weighs $2-5 \mathrm{~g}$, although stones up to $10 \mathrm{~g}$ are common. Rare pieces are found that attain weights of $100-300+g$.

M ozambique Gems has performed systematic mapping and test pitting of their concession (figure 13), and has completed a comprehensive environmental impact report. At the time of the authors' visit, the company employed 32 workers, mostly from the local area. The company is building a washing plant capable of processing 150-200 tonnes of material per day (figure 14). It is modeled after plants used for recovering al luvial al exandrite in Brazil, and Brazilians are doing the design and construction. The plant will employ water jets to break up the mined material and wash it through a series of three screens with mesh sizes of 2,1 , and $0.5 \mathrm{~cm}$. Material from the three screens will be routed to large tables and then hand-picked for tourmal ine.

Mechanized mining will begin when the washing plant is completed, which is projected for mid-2008.

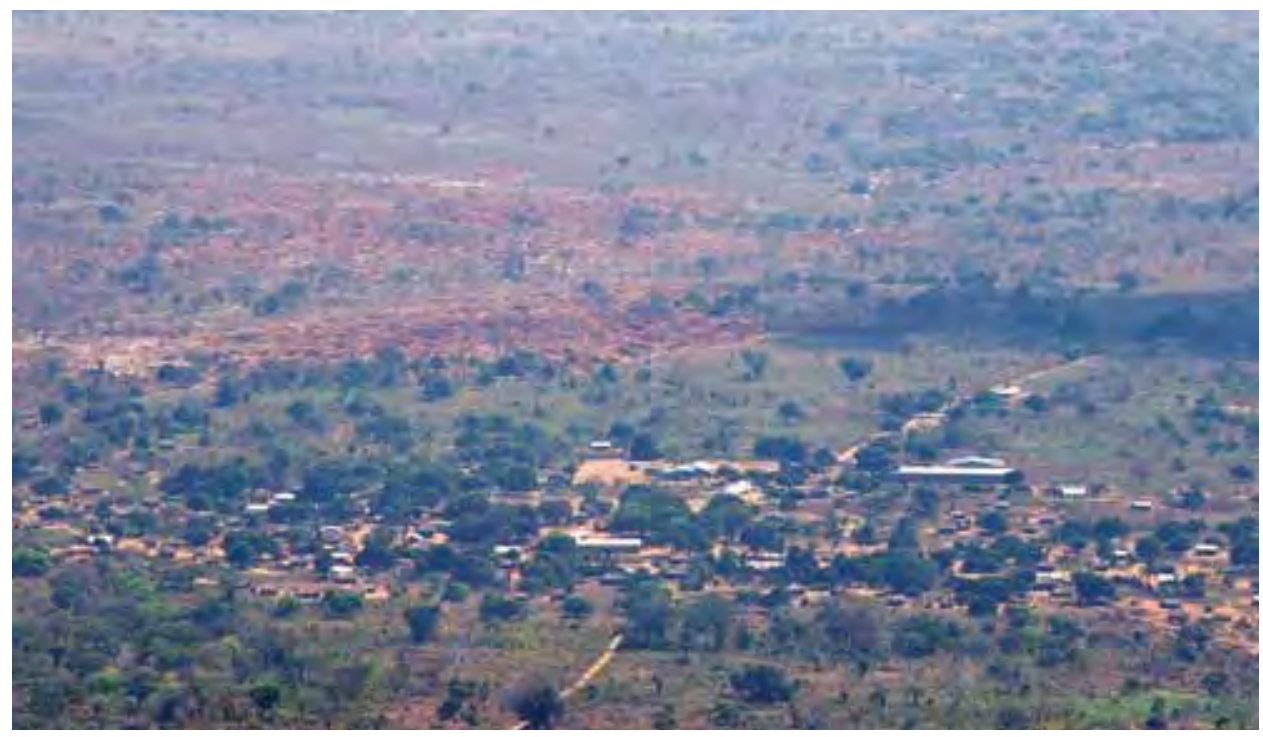

Figure 10. This view of the Mavuco area from the top of Mt. Muli (a few kilometers to the south) shows a portion of the town in the fore ground, and the weathered red-brown laterite that denotes the mining area in the background. Photo by B. M. Laurs. 


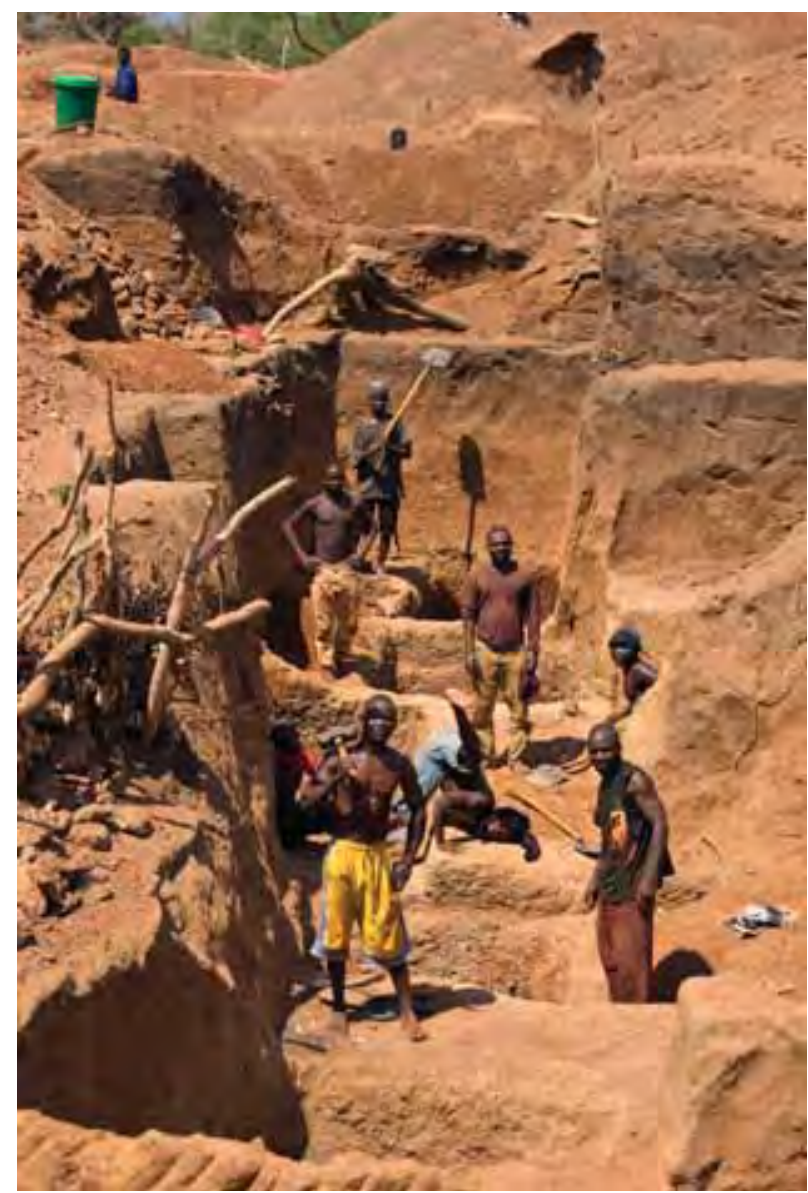

Figure 11. Most of the Cu-bearing tourmaline recovered so far from the Mavuco area has come from artisanal miners. Working in small groups, they use picks and shovels to dig through the laterite overburden in search of the gem-bearing layer. Photo by B. M. Laurs.

Figure 13. Mozambique Gems is digging this test pit to help determine the extent of the tourmaline-bearing layer on their concession. The material from the gembearinglayer of the pit will be washed, screened, and hand-picked for tourmaline. Photo by B. M. Laurs.

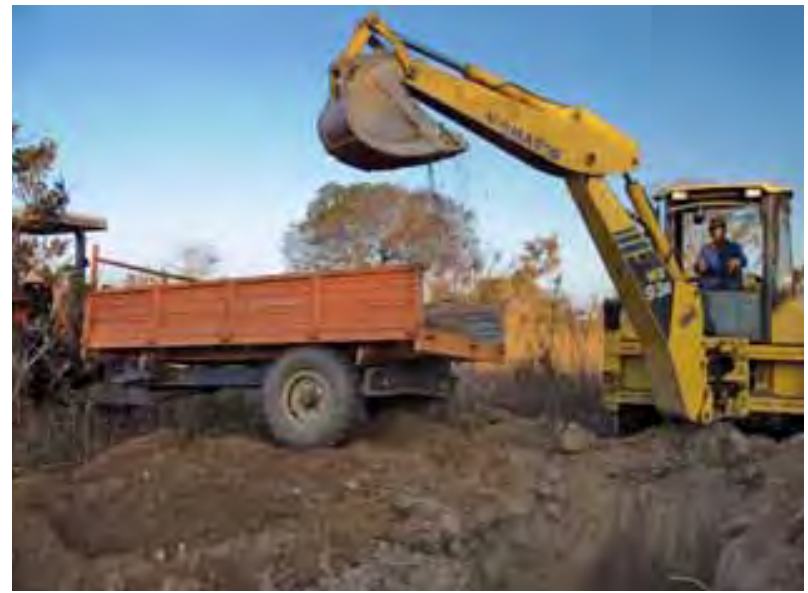

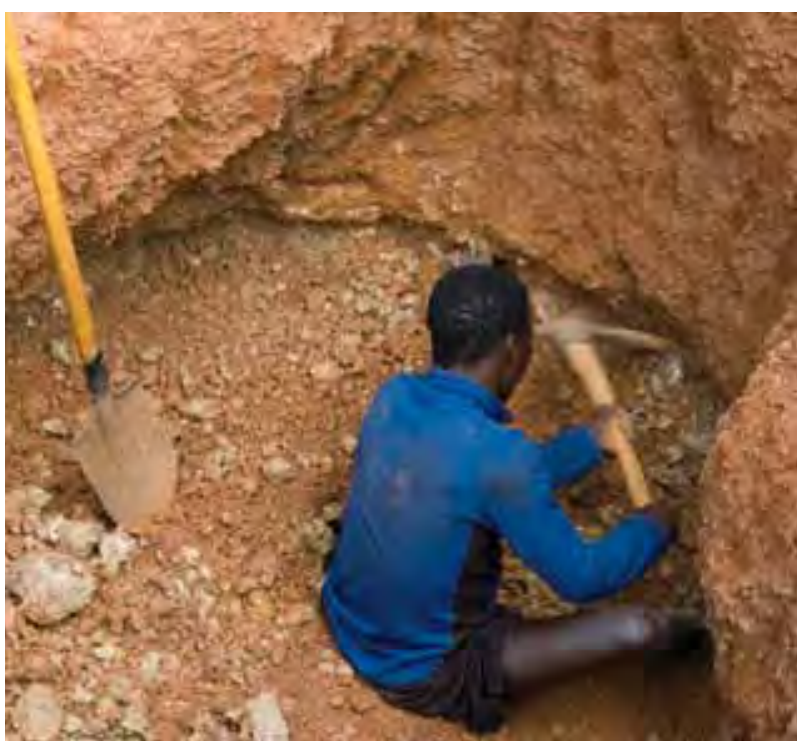

Figure 12. When they reach the tourmaline-bearing layer, the miners search for the gems by digging through the gravels with a pick. Photo by B. M. Laurs.

A bulldozer will excavate a series of elongate pits to reach the tourmal ine-bearing layer. The topsoil will be stockpiled, and miners will reclaim each pit before proceeding to the next one. All of the material excavated from the tourmaline-bearing layer will be put through the washing plant. Water will be pumped to the plant from a local stream, and once

Figure 14. This washing plant, constructed by

Mozambique Gems, will be able to process 150-200 tonnes of material per day when it is completed. Photo by J. C. Zwaan.

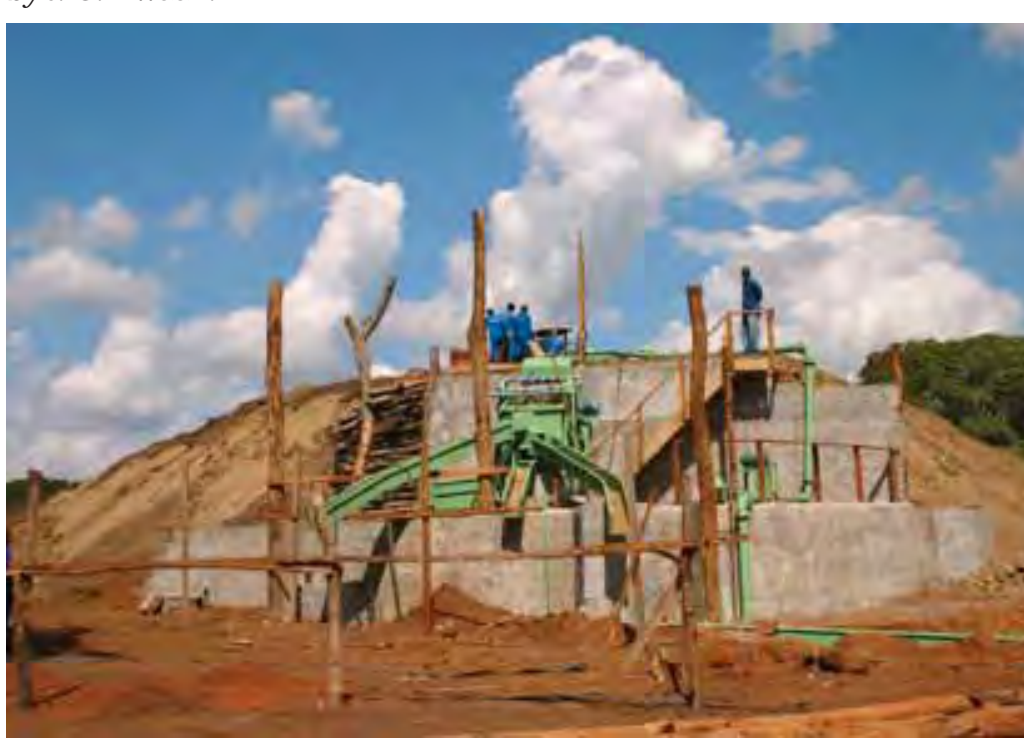




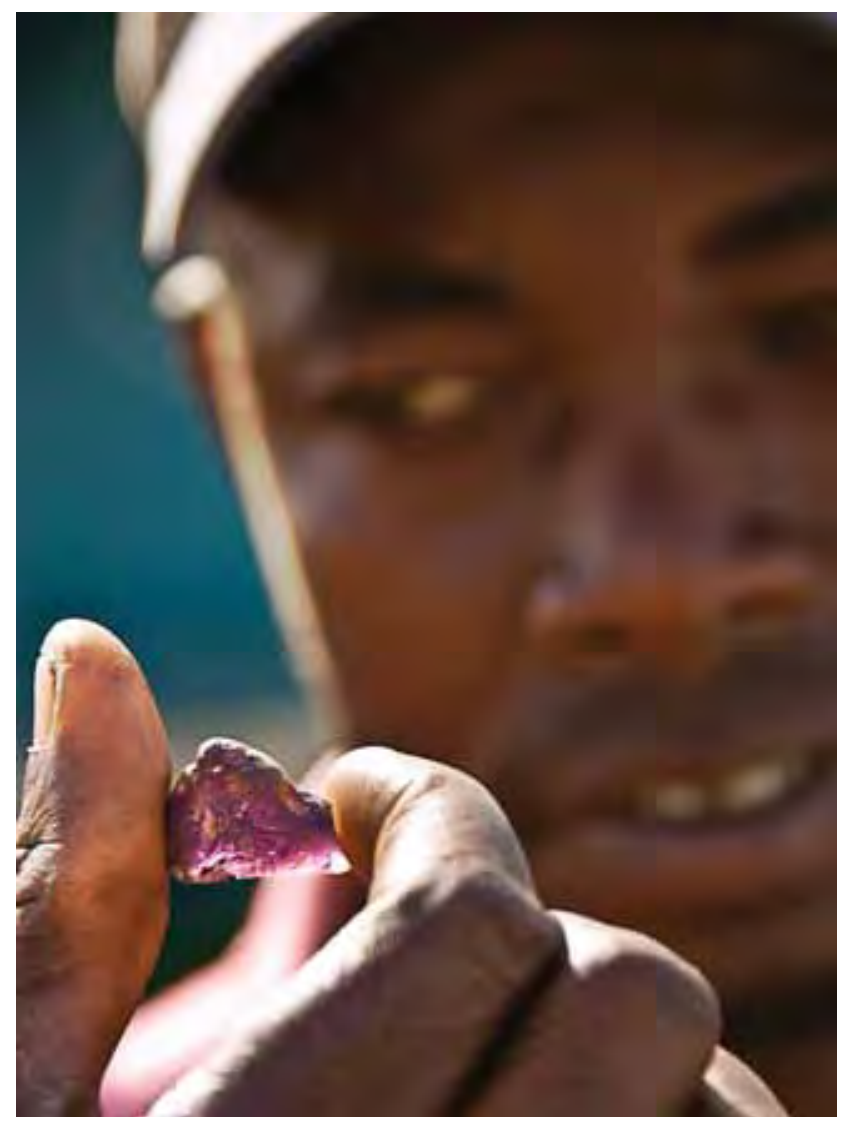

arrive on the market, it was impossible to determine the overall production of rough from Mavuco.

Considerable amounts of the tourmaline produced by artisanal miners have been sent to Hong Kong and Germany for cutting. According to M r. Konate (pers. comm., 2007), the tourmal ine obtai ned so far by M ozambique Gems has been cut in Brazil, where heating is done to the preformed gems. In the future, their production will be channel ed directly to large cutting wholesalers and television shopping networks, mainly for U.S. and Japanese markets.

While in Nampula, authors BM L and JCZ examined two parcels of rough material (one about $1 \mathrm{~kg}$ and the other 400 grams) that were reportedly unheated goods mined from the M avuco area. They showed a variety of colors, clarities, and sizes (again, see figure 9), with some weighing as much as $30 \mathrm{~g}$. We purchased a selection of smaller samples from the $1 \mathrm{~kg}$ parcel for analysis (figure 18), some of which later proved to be imitations: bluish green manufactured glass, yellowish green fluorite, and amethyst. According to one dealer who has visited the Mavuco area (F. Hashmi, pers. comm., 2007), bluish green glass frequently appears in rough parcels offered for sale throughout East Africa. Amethyst is used as an

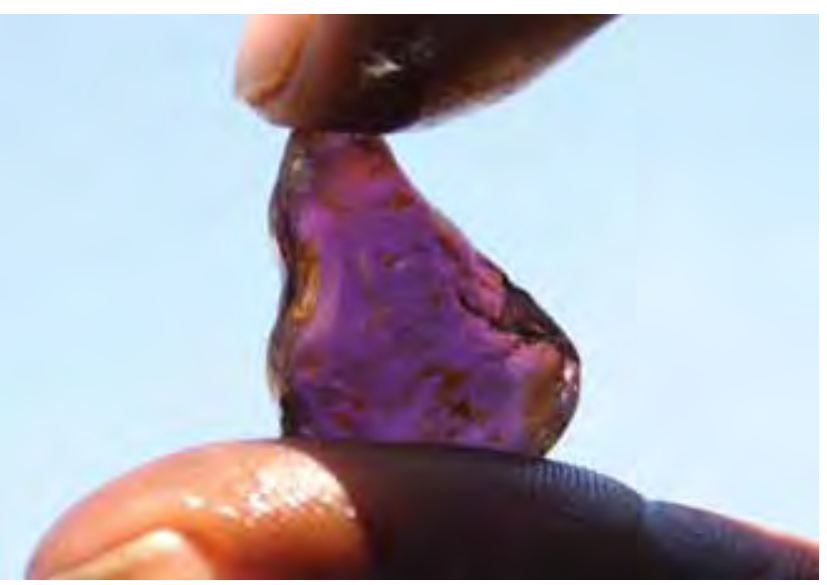

Figure 17. This intense multicolored bluish violet to pink waterworn tourmal ine pebble, which weighs $6 \mathrm{~g}$, was offered for sal e at Mavuco. Photos by B. M. Laurs (left) and J. C. Zwaan (above).

imitation because it resembles the color of Cu-bearing tourmal ine that commonly heat-treats to "neon" blue colors. During our trip, Mr. Konate mentioned that pieces of "tumbled" amethyst are produced by shaking them in an empty soda bottle until they take on a worn appearance. Milisenda et al. (2006) also documented a non-Cu-bearing tourmaline crystal and a flame-fusion synthetic ruby "pebble" that were represented as being M ozambique Cu-tourmaline.

Figure 18. These unheated waterworn pebbles (0.3$1.1 \mathrm{~g}$ ) were obtained in Nampula for characterization as part of this study. Three of the samples proved to be imitations: an amethyst (the somewhat triangular purple fragment on the left), a very light yel lowish green fluorite (the rectangular piecejust to the right of center), and a very light bluish green manufactured glass (below the fluorite). Photo by Kevin Schumacher.

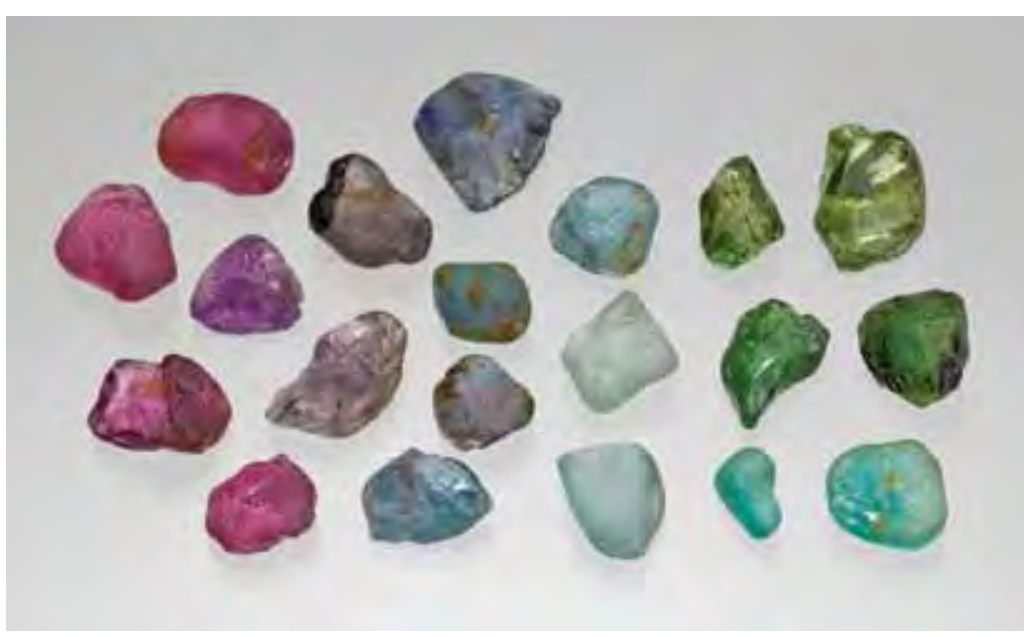




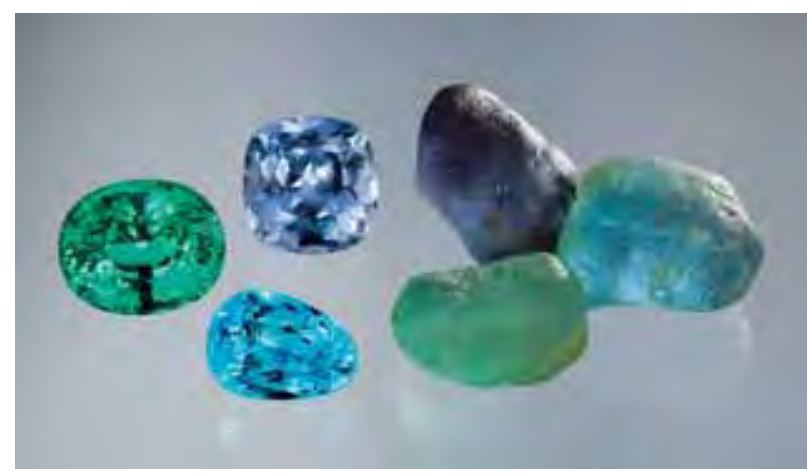

Figure 19. Mozambique Cu-bearing tourmaline pebbles commonly are of a singl e color, yiel ding cut stones with even color distribution (here, 6.75-15.77 ct). All but the bluefaceted stone are unheated. Courtesy of Barker \& Co. and Pala International; photo (CHarold \& Erica Van Pelt.

While much of the tourmaline rough is monochromatic and yields stones of a single hue (figure 19), some pieces show noticeable color zoning, commonly in irregular patterns (figure 20). A small number of dramatic multicolored stones have been cut from the color-zoned material (figure 21). Since heat treatment reduces the violet/purple hue (see below), such stones are highly unlikely to have been heated. Most of the faceted tourmaline from Mavuco weigh 1-4 ct. Stones weighing 5-20 ct are produced occasionally, and clean faceted gems in the $20-60+c t$ range are rare but nevertheless more common than among Paraí ba-type tourmal ines from other local ities.

Figure 21. This $2.55 \mathrm{ct}$ faceted Cu-bearing tourmaline from Mozambique shows striking color zoning. The presence of purple and violet in this stone strongly indicates that it is unheated. Courtesy of Mayer and Watt, Maysville, Kentucky; photo by Robert Weldon.

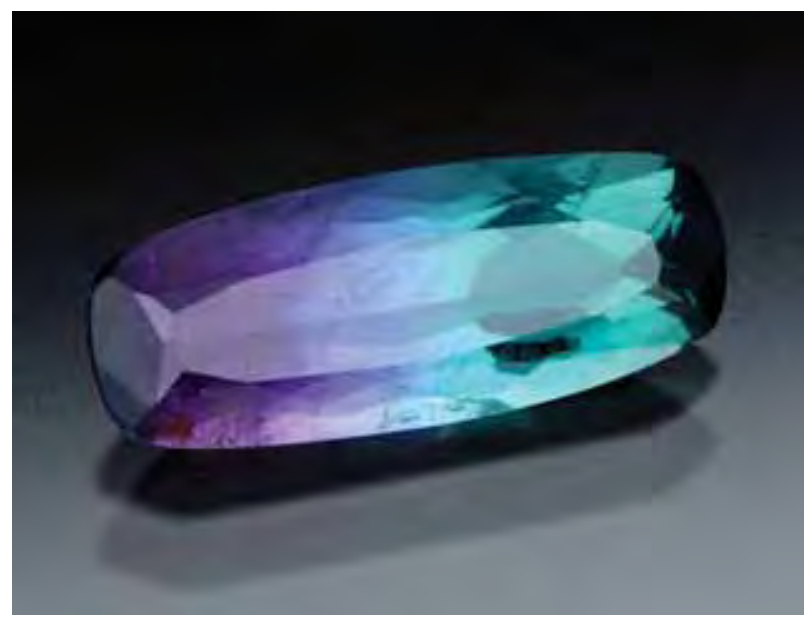

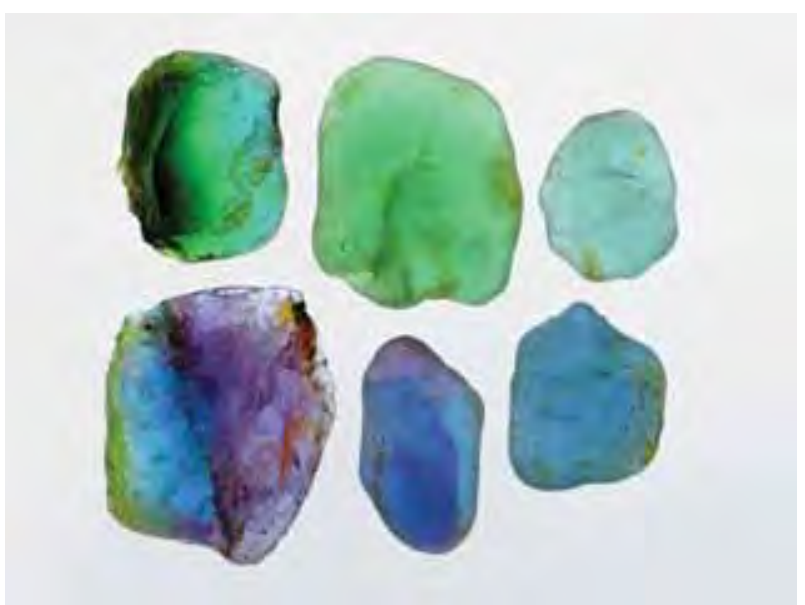

Figure 20. Some of the rough tourmaline have vivid color zoning. Thestones shown here, which are all unheated, range from 6 to $11 \mathrm{~g}$. Courtesy of Barker \& Co. and Pala International; photo by C. D. Mengason.

\section{MATERIALSAND METHODS}

For this study, we examined 106 samples of M ozambique Cu-bearing tourmaline, including 59 pieces of rough $(0.1-4.1 \mathrm{~g})$ and 47 faceted stones $(0.40-17.49 \mathrm{ct})$. All the rough samples were transparent and suitable for faceting or cabbing; at least two windows were polished on each. The rough consisted of 17 samples obtained by authors BML and JCZ from a local deal er in $\mathrm{N}$ ampula, who represented them as unheated tourmaline from the Mavuco area (again, see figure 18); and 21 pairs of samples (42 total) donated by two U.S. dealers to show the effects of heat treatment (e.g., figure 22). The faceted samples included 12 unheated stones (e.g., figure 23) and 11 pairs (22 total) of unheated/heated stones (figure 24) that were tested at the Netherlands Gemmological Laboratory (NGL); as well as 13 unheated tourmalines that were examined at the GIA Laboratory in New York (figure 25). All the faceted samples were obtained from U.S. dealers, who had purchased the material from reliable suppliers as coming from Mozambique. Mavuco is the only known source of Cu-bearing tourmal ine in M ozambique.

The two plates from each of the 21 unheated/ heated pairs of rough were cut from the same piece of rough. One of the dealers (Bill Barker) heated one sample from each pair in air to $530^{\circ} \mathrm{C}$ for three hours. To minimize thermal shock, he packed the samples in plaster-of-paris powder and raised and lowered the temperature gradually. After heating, these samples were soaked in warm oxalic acid at GIA for several days to remove iron staining and improve the observation and comparison of colors. Mr. Barker selected 


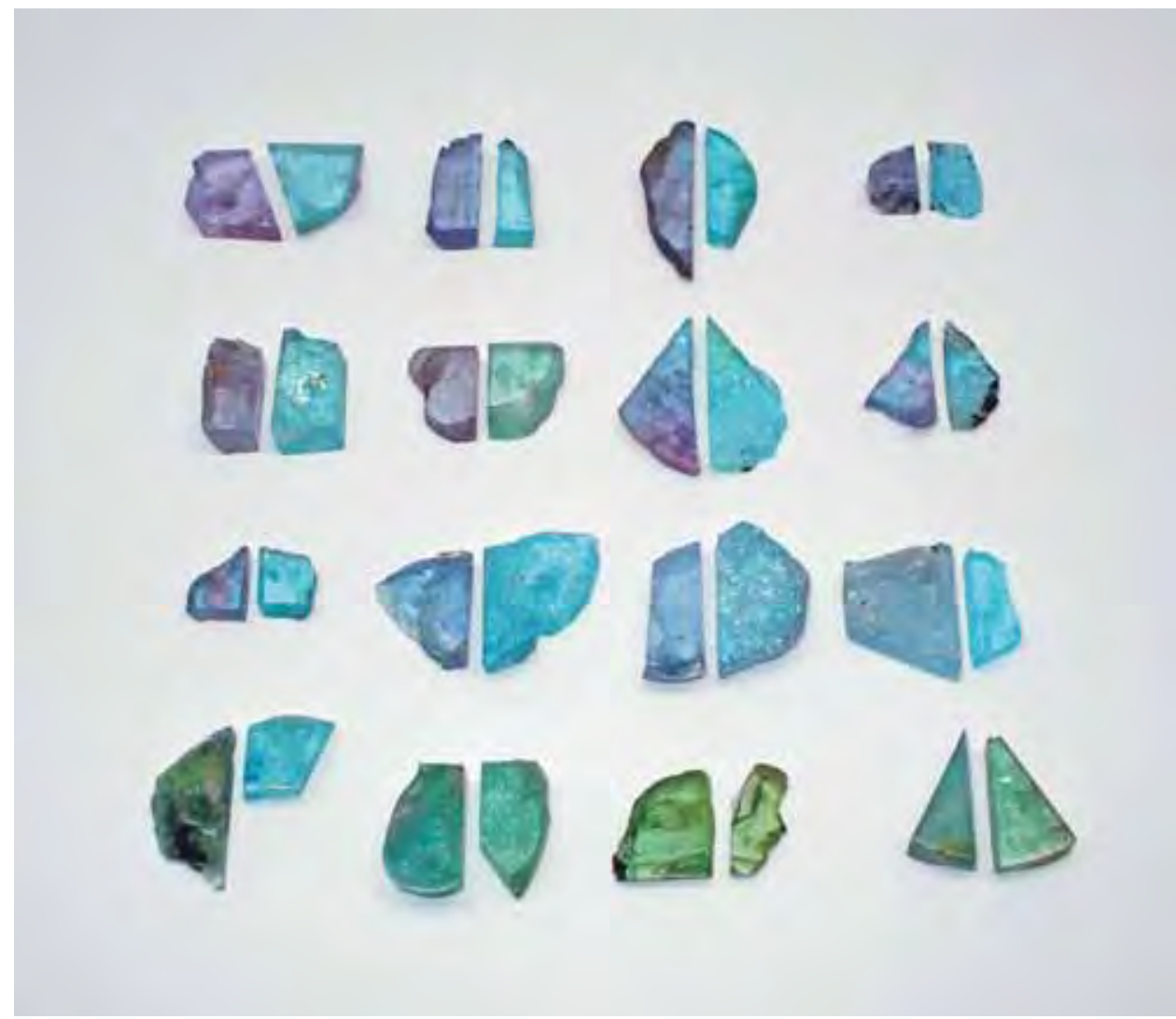

Figure 22. Each pair of parallel-polished plates shown here (0.98-7.15 ct) was sliced from the same piece of rough. The segments on the left in each pair are unheated, and those on the right were heated to $530^{\circ} \mathrm{C}$ for three hours. These slices formed part of the study suite of samples examined before and after heating. Gift of Barker $\&$ Co. and Pala International, GIA Collection nos. 3751937540; photo by J. C. Zwaan.

the 11 unheated/heated pairs of cut stones to show the typical effects of heat treatment on the coloration of these tourmalines; the stones in each pair are similar in size and shape, but they were not faceted from the same piece of rough. Mr. Barker informed us that he brought the heated samples in each pair to $550^{\circ} \mathrm{C}$ for three hours.

Testing at NGL was done on all the rough samples and on 34 of the faceted samples described above; included were standard gemological properties and energy-dispersive X-ray fluorescence (EDXRF) spectrometry. Instruments and methods used for determination of standard gemological properties included a Rayner refractometer (yttrium aluminum garnet prism) with a near sodium-equivalent light source to measure refractive indices and birefringence; hydrostatic determination of specific gravity; a calcite dichroscope for observation of pleochroic colors; four-watt long- and short-wave UV lamps used in a darkened room to observe fluorescence; a Nikon Eclipse E600 POL polarizing microscope; and both standard daylight and incandescent illumination for the observation of colors. An Eagle mProbe EDXRF spectrometer was used to anal yze the composition of one surface-reaching inclusion, as well as the composition of a rough sample that proved to be an imita- tion, and to survey the chemistry of the sediment in which the tourmalines are found. In addition, Raman spectroscopy of inclusions in 26 samples (7 unheated cut stones, and 7 heated and 12 unheated pieces of

Figure 23. These $\mathrm{Cu}$-bearing tourmal ines from Mozambique (1.69-3.76 ct), which were characterized for this report, show a wide range of natural, unheated colors. Courtesy of Barker \& Co. and Pala International; photo by J. C. Zwaan.

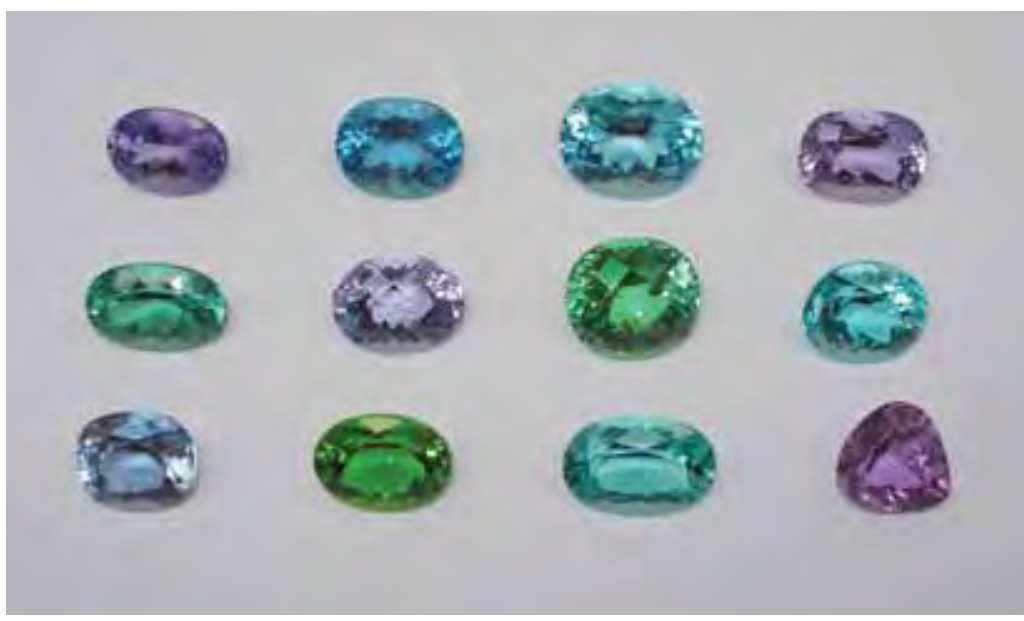



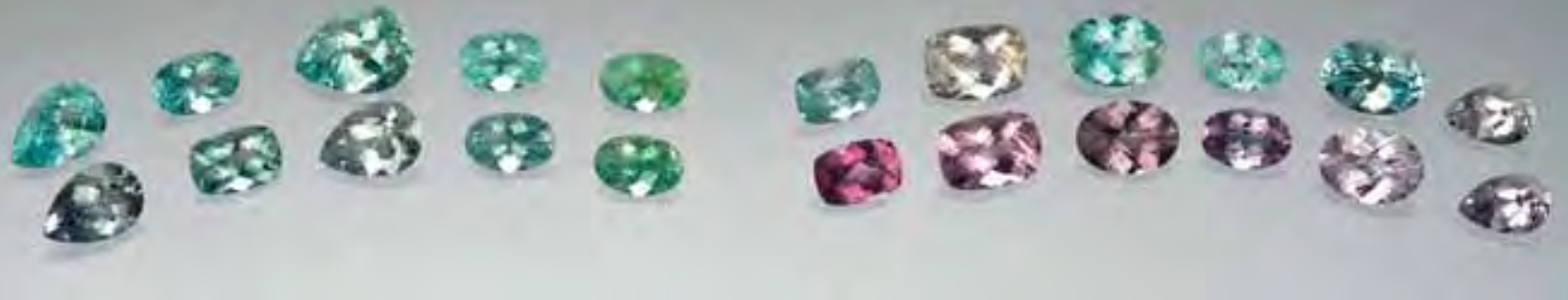

Figure 24 . These faceted Cu-bearing tourmal ines $(0.42-0.85 \mathrm{ct}$ ) were carefully selected to show typical colors before (bottom row) and after (top row) heat treatment. The sample pairs were not cut from the same pieces of rough.

Courtesy of Barker \& Co. and Pala International; photo by Robert Weldon.

rough) was performed by JCZ at the CCIP French Gemmological Laboratory in Paris using a Renishaw Invia instrument with $514 \mathrm{~nm}$ laser excitation.

The examination of 13 faceted stones at the GIA Laboratory in $\mathrm{New}$ York included determination of standard gemological properties, as well as polarized UV-Vis-NIR spectroscopy using a Perkin-Elmer Lambda 950 spectrophotometer with a cal cite polarizer over the range $250-850 \mathrm{~nm}$ with a resolution of $1 \mathrm{~nm}$. Gemological testing included daylight-equivalent (D65) light for color and a GIA Duplex II refractometer for RI and birefringence. M ethods for deter- mining SG, pleochroism, fluorescence, and internal features were comparable to those used at NGL. The GIA Laboratory in Carlsbad performed Vis-N IR absorption spectroscopy (400-1000 $\mathrm{nm}$ range) on the 21 unheated/heated pairs of polished rough, using a Hitachi U 4001 spectrometer with a slit width of 2.0 $\mathrm{nm}$, data collection interval of $1.0 \mathrm{~nm}$, and scan speed of $120 \mathrm{~nm} / \mathrm{min}$. Spectra were collected at room temperature using an unpolarized light beam focused through the parallel polished samples.

The quantitative chemical composition of all 59 rough samples was measured by electron micro-

Figure 25. These unheated Cu-bearing tourmal ines from Mozambique were al so studied for this report. The 1.28-3.02 ct stones on the left are courtesy of Pala I nternational; the less common colors on the right (3.71-17.49 ct, top; 80.54 ct, bottom) are courtesy of Fine Gems International. Photos by Robert Weldon.

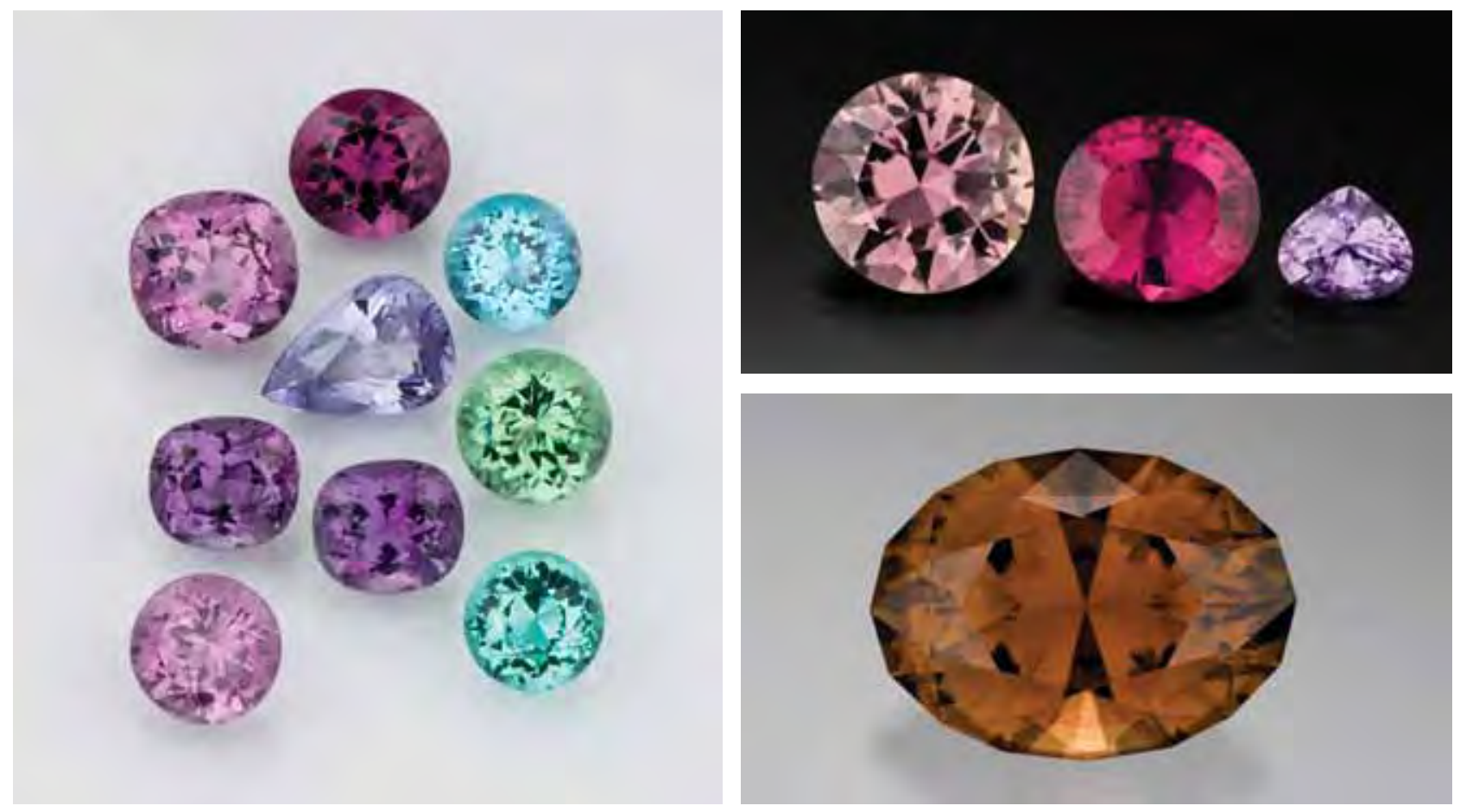


TABLE 1. Physical properties of Cu-bearing tourmaline from Mavuco, Mozambique.

\begin{tabular}{|c|c|c|c|c|c|c|}
\hline \multirow{2}{*}{ Properties } & \multicolumn{4}{|c|}{$\begin{array}{l}\text { Unheated } \\
\text { (no. samples) }\end{array}$} & \multicolumn{2}{|c|}{$\begin{array}{c}\text { Heated } \\
\text { (no. samples) }\end{array}$} \\
\hline & 16 & 29 & 14 & 15 & 26 & 6 \\
\hline $\begin{array}{l}\text { Color } \\
\text { (standard daylight) }\end{array}$ & $\begin{array}{l}\text { Very light to medium } \\
\text { purple to reddish } \\
\text { purple; very slightly } \\
\text { grayish to strong } \\
\text { saturation }\end{array}$ & $\begin{array}{l}\text { (Medium) light } \\
\text { (violetish) blue to } \\
\text { (medium) light (bluish) } \\
\text { violet; grayish to } \\
\text { moderately strong } \\
\text { saturation }\end{array}$ & $\begin{array}{l}\text { Light bluish green to } \\
\text { light greenish blue; } \\
\text { most often moderately } \\
\text { strong and strong } \\
\text { saturation }\end{array}$ & $\begin{array}{l}\text { Very light to medium } \\
\text { green to yellowish } \\
\text { green; moderately } \\
\text { strong to vivid } \\
\text { saturation }\end{array}$ & $\begin{array}{l}\text { Light bluish green } \\
\text { to light greenish } \\
\text { blue; moderately } \\
\text { strong to strong } \\
\text { saturation }\end{array}$ & Light to medium green \\
\hline $\begin{array}{l}\text { Color } \\
\text { (incandescent light) }\end{array}$ & (Purplish) pink & $\begin{array}{l}\text { Light (grayish) green } \\
\text { to light (greenish) gray }\end{array}$ & Same & Same & Same & Same \\
\hline Pleochroism & Weak to strong & Weak to distinct & Weak to distinct & Weak to strong & Weak to distinct & Weak to distinct \\
\hline e-ray & $\begin{array}{l}\text { Pink, pale yellow, } \\
\text { brownish/pinkish } \\
\text { orange, purple }\end{array}$ & $\begin{array}{l}\text { Light (grayish) pink, } \\
\text { gray to green, light } \\
\text { brown }\end{array}$ & $\begin{array}{l}\text { Light greenish gray } \\
\text { to (grayish) green }\end{array}$ & $\begin{array}{l}\text { Light gray to grayish } \\
\text { green, green to bluish } \\
\text { green }\end{array}$ & $\begin{array}{l}\text { Light gray, grayish } \\
\text { green, yellowish to } \\
\text { bluish green }\end{array}$ & $\begin{array}{l}\text { Light (greenish) gray } \\
\text { to grayish green }\end{array}$ \\
\hline o-ray & $\begin{array}{l}\text { Medium(-light) purple } \\
\text { to violet to pink, } \\
\text { violetish blue }\end{array}$ & $\begin{array}{l}\text { Light blue to violet } \\
\text { (greenish) blue }\end{array}$ & $\begin{array}{l}\text { Light bluish green to } \\
\text { green }\end{array}$ & $\begin{array}{l}\text { Medium (yellowish) } \\
\text { (greenish) blue }\end{array}$ & $\begin{array}{l}\text { Light bluish green to } \\
\text { (yellowish) green }\end{array}$ & Light to medium \\
\hline \multicolumn{7}{|c|}{ 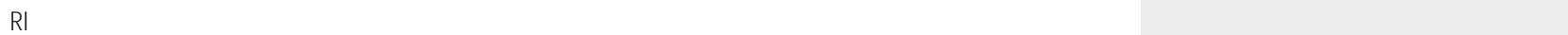 } \\
\hline & $\begin{array}{l}1.638-1.640 \\
1.620-1.622\end{array}$ & $\begin{array}{l}1.638-1.642 \\
1.619-1.623\end{array}$ & $\begin{array}{l}1.638-1.640 \\
1.620-1.621\end{array}$ & $\begin{array}{l}1.640-1.643 \\
1.620-1.623\end{array}$ & $\begin{array}{l}1.638-1.643 \\
1.618-1.623\end{array}$ & $\begin{array}{l}1.639-1.643 \\
1.620-1.623\end{array}$ \\
\hline Birefringence & $0.018-0.020$ & $0.018-0.020$ & $0.018-0.020$ & $0.018-0.021$ & $0.018-0.020$ & $0.019-0.020$ \\
\hline SG & $3.01-3.06$ & $3.01-3.06$ & $3.03-3.09$ & $3.06-3.09$ & $3.03-3.07$ & $3.06-3.09$ \\
\hline $\begin{array}{l}\text { UV fluorescence } \\
\text { (long- and short- } \\
\text { wave) }\end{array}$ & $\begin{array}{l}\text { Inert except for two } \\
\text { samples }^{\mathrm{a}}\end{array}$ & Inert & Inert & Inert & $\begin{array}{l}\text { Inert; } 13 \text { faint blue } \\
\text { to long-wave }\end{array}$ & $\begin{array}{l}\text { Inert; two faint blue } \\
\text { to long-wave }\end{array}$ \\
\hline Internal features & \multicolumn{4}{|c|}{$\begin{array}{l}\text { - Partially healed fissures ("fingerprints") with isolated two-phase (liquid-gas) inclusions, with } \\
\text { irregular, wispy/thready, and triangular shapes, also in almost pinpoint size } \\
\text { - Partially healed fissures with "trichites," reflective thin films, and long, spiky inclusions } \\
\text { - Hollow tubes, long and generally thin and narrow, oriented parallel to the c-axis, occasionally } \\
\text { in discrete planes or forming "walls"; may be stained yellow to red-brown and contain hematite } \\
\text { - Straight growth zoning } \\
\text { - Color zoning (one sample) } \\
\text { - Mineral inclusions (not common): quartz, both isolated and within fluid inclusions; lepidolite; } \\
\text { and sodic plagioclase }\end{array}$} & \multicolumn{2}{|c|}{$\begin{array}{l}\text { In addition to the features listed for the } \\
\text { natural colors: } \\
\text { - Minute cracks, usually small, with } \\
\text { discoid and more elongated shapes, } \\
\text { appearing milky or brownish, depending } \\
\text { on the lighting } \\
\text { - (Larger) voids in partially healed fissures } \\
\text { may appear frosty and dried out }\end{array}$} \\
\hline
\end{tabular}

${ }^{a}$ A brownish reddish purple stone (figure 25, top right-far left sample) fluoresced weak white to long-wave UV; an orangy brown stone with reddish purple components (figure 25, bottom) fluoresced white under the girdle to short-wave UV and irregular weak yellow to long-wave UV.

probe at the University of N ew Orleans. Data were collected using an ARL-SEM Q electron microprobe with $15 \mathrm{kV}$ (for sodium) and $25 \mathrm{kV}$ accelerating voltages, $15 \mathrm{nA}$ beam current, and a $3 \mu \mathrm{m}$ beam diameter. The measurements were calibrated with natural mineral and synthetic compound standards, and a ZAF correction procedure was applied to the data.

Trace-element chemical data of all the rough samples were measured quantitatively at the GIA Laboratory in Carlsbad using a Thermo X Series ICPMS (inductively coupled plasma-mass spectrometer) joined to a N ew Wave UP-213 laser-ablation sampling system. The laser operated at a wavelength of $213 \mathrm{~nm}$ with $\mathrm{He}$ as the carrier gas (flow rate of $\sim 1$ liter/minute). Laser-ablation parameters were as follows: $40 \mu \mathrm{m}$ spot diameter, $-10 \mathrm{~J} / \mathrm{cm}^{2}$ laser energy density (fluence), $7 \mathrm{~Hz}$ repetition rate, and 25 second laser dwell time. For calibration, NIST SRM 610, 612 , and 614 glass reference materials (Pearce et al.,
1996) were used as external standards, and boron was used as an internal standard. An average B concentration for elbaite tourmaline of 3.26 wt.\% was obtained from Deer et al. (1974).

In the course of this testing, four pebbles obtained in Mozambique by authors BML and JCZ proved to be imitations. The amethyst, light yellowish green fluorite, and light bluish green manufactured glass (agai n, see figure 18) purchased from one of the parcels were initially detected during microprobe anal ysis. A piece of light green rough that was obtained directly from one of the miners at the pits was identified as fluorite during gemol ogical testing at NGL.

\section{GEMOLOGICAL PROPERTIES}

The gemological properties of the rough and cut tourmalines are summarized in table 1, with details described below. 

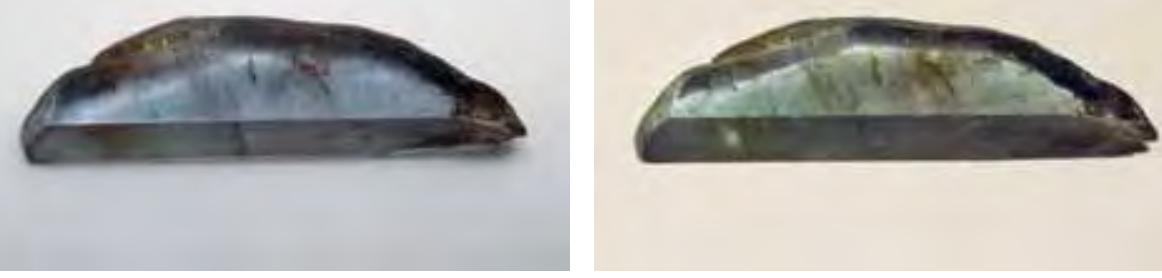

Figure26. This unheated tourmaline $(4.13 \mathrm{ct})$ shifted from grayish blue in fluorescent light (left) to grayish green in incandescent light (right). Photos by J. C. Zwaan.

Visual Appearance and Color. The rough tourmaline seen in Mozambique by the authors consisted of well-rounded waterworn pebbles (again, see figures 9 and 17-19) and broken fragments, in various colors including blue or violet, very light blue, strong greenish blue, purple, and green (for complete color descriptions, see the $G \& G$ Data Depository at www.gia.edu/gemsandgemology). Typically the color was evenly distributed, although we did see strong color zoning in some of the rough. One greenish blue piece had a pink core; other greenblue samples showed pinkish purple zones, while one blue-green crystal section had a dark green rim. On one side of a violetish blue sample, a gradual transition to greenish blue was observed. In some waterworn pebbles, portions of the original crystal faces could be recognized. Most of the material were transparent, but we also saw heavily included stones.

The cut and rough (most facetable, some cabochon quality) tourmalines we studied showed a wide variety of col ors (again, see figures 22-25). The main color groups (in daylight-equivalent illumination) of the unheated samples were purple to reddish purple, blue to bluish violet, bluish green to greenish blue, and green to yellowish green. Color banding was observed only rarely in our samples. Many of the heated tourmalines were bluish green to greenish blue, colors produced from blue-to-violet starting material (figure 22). Some of our heated samples were green, which resulted from heating darker green or yellowish to slightly bluish green stones (see again figure 22 and "UV-Vis-N IR Spectroscopy" below). The dichroism of the cut tourmalines varied from weak to strong.

When viewed in incandescent light, the unheated light blue to violet tourmal ines appeared light green to gray (figure 26). Most of the purple stones appeared pink and purplish pink or red in incandescent light. However, there was no obvious color change shown by a light purple piece of rough and a medium, slightly grayish purple cut stone.

Physical Properties. N early $80 \%$ of the stones tested showed refractive indices of $n_{0}=1.638-1.641$ and $n_{e}$ $=1.619-1.622$, with a bi refringence ranging between 0.018 and 0.020 . Although overlapping, some green tourmal ines showed slightly higher average values of $n_{0}=1.640-1.643$ and $n_{e}=1.621-1.622$, with $a$ bi refringence of 0.019-0.021.

Figure 27. In Cu-bearing tourmal ine from Mavuco, partially heal ed fissures show a wide variation in appearance, as illustrated in these unheated samples. They commonly occur as "trichites," consisting of flat and irregularly fluid-filled cavities that are connected by thin capillaries (left, magnified 65×). Some of the cavities are larger and less flat, with obvious bubbles when viewed with transmitted light (center; magnified 40x). In some of the fissures, isolated two-phase (liquid-gas) inclusions were abundant (right, magnified 65×). Photomicrographs by J. C. Zwaan.
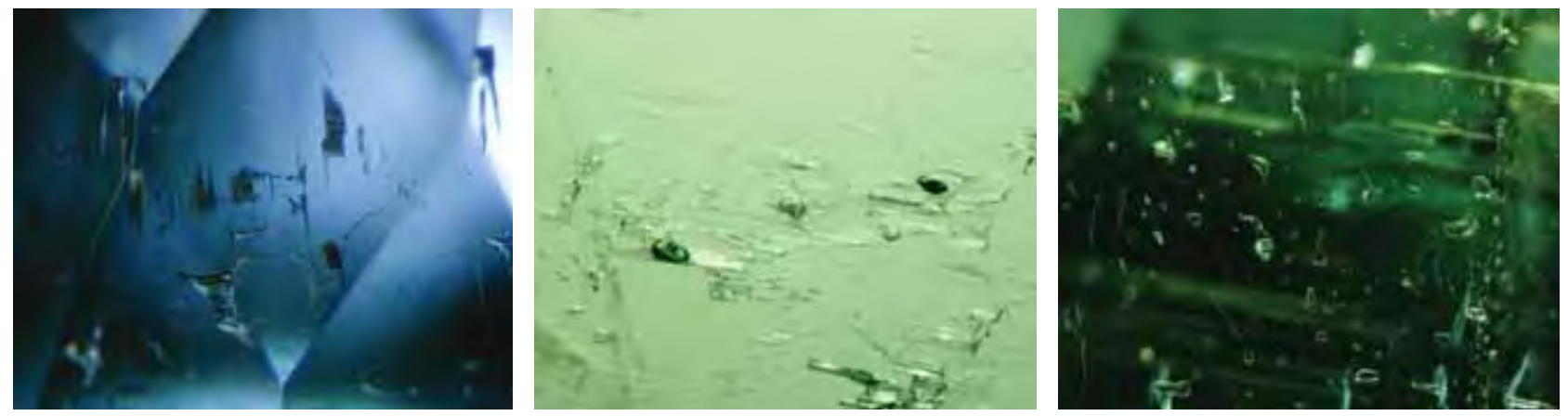

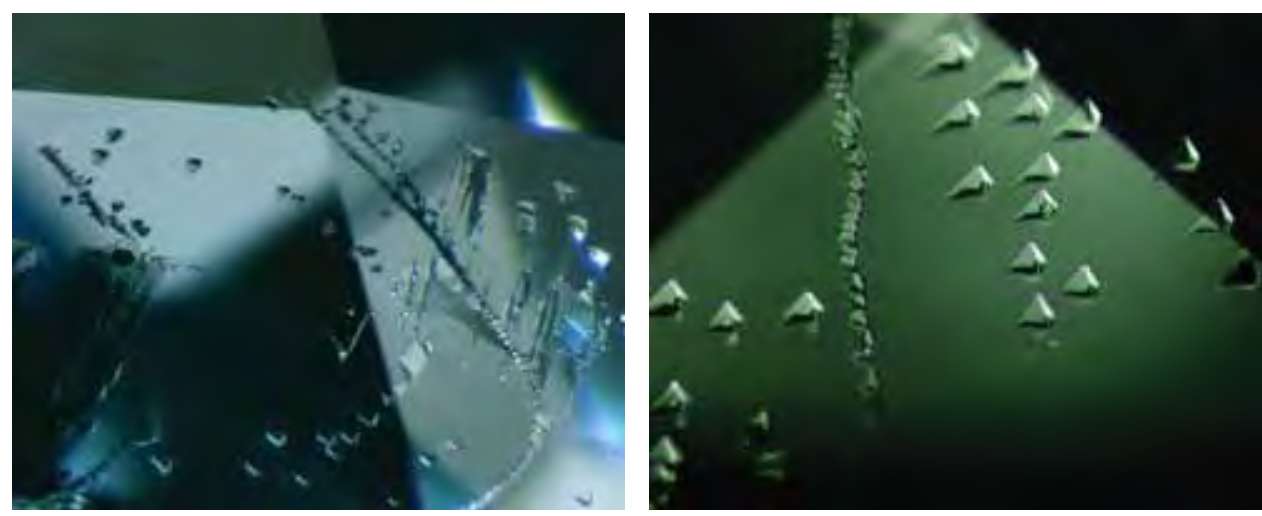

Figure 28. This partially healed fissure in an unheated tourmaline has a network of oriented triangular two-phase (liquidgas) inclusions, with some isolated and others in close array (left, magnified 75×). Higher magnification clearly shows the bubbles present in each triangular inclusion (right, magnified 100x). Photomicrographs by J. C. Zwaan.

Specific gravity values ranged from 3.01 to 3.09 . The majority of the stones had an SG between 3.04 and 3.06, while the green tourmalines showed slightly higher values of 3.06-3.09.

All but two of the tourmalines that were represented as unheated were inert to long- and shortwave UV radiation. Almost half of the known heattreated stones fluoresced a faint blue to long-wave UV, and nearly half of those also fluoresced very faint blue to short-wave UV.

Microscopic Characteristics. The rough and cut samples ranged from very slightly to heavily included. The main internal characteristics in both the heated and unheated samples were partially heal ed fissures (showing various stages of heal ing), fluid inclusions, and growth tubes (commonly stained). In addition, numerous minute cracks were seen in many of the heated stones.

Fluid Inclusions, Growth Tubes, and Cracks. The most conspicuous inclusions consisted of partially healed fissures, which exhibited wide variations in appearance (figure 27). Often they occurred as "trichites" (i.e., fluid-filled cavities connected by networks of very thin capillaries). The capillaries were irregular and coarse, wispy, or thread-like. The cavities were typically flattened and irregularly shaped (figure 27, left), but more equidimensional (or less flattened) cavities were often present. In the larger cavities, a bubble could sometimes be seen in transmitted light (figure 27, center). Some partially healed fissures were marked by abundant isolated two-phase (liquid-gas) inclusions (figure 27, right). Typically these inclusions were irregular and wispy, but in some cases triangular shapes were predominant, either isolated or in groups (figure 28). Some partially healed fissures contained very small, pinpoint-sized features that could be resolved as twophase inclusions under $200 \times$ magnification. The two-phase inclusions showed low relief, with bubbles that were small relative to the size of the inclusion, indicating that they are rich in liquid water (e.g., Samson et al., 2003). Occasionally, they contained small doubly refractive minerals as well (see "Mineral Inclusions" below).

More-or-less parallel-oriented and interconnected flat channels and long, spiky inclusions-apparently representing a relatively early discontinuation of fracture healing-were occasionally encountered (figure 29). Hollow tubes, oriented parallel to the c-axis, were quite common (figure 30). They were present as one or two isolated tubes in "clean" stones, but al so occurred more abundantly, occasionally even forming "walls" of parallel tubes in straight or slightly wavy planes. Both the narrow

Figure 29. Subparallel-oriented and interconnected flat channels and long, spiky inclusions, such as seen here in an unheated tourmaline, are occasionally encountered. These features appear to represent an early discontinuation of fracture healing. Photomicrograph by J. C. Zwaan; magnified 55×.

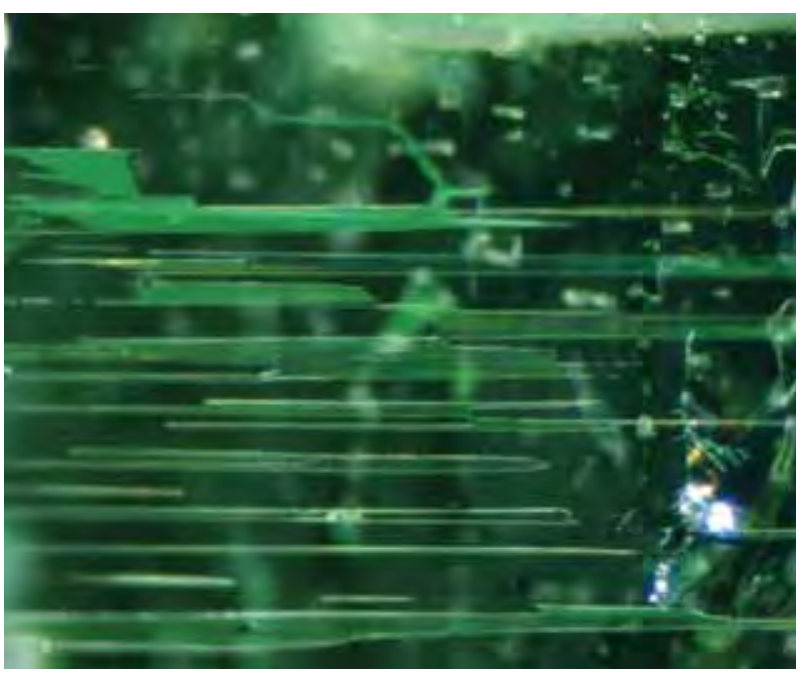




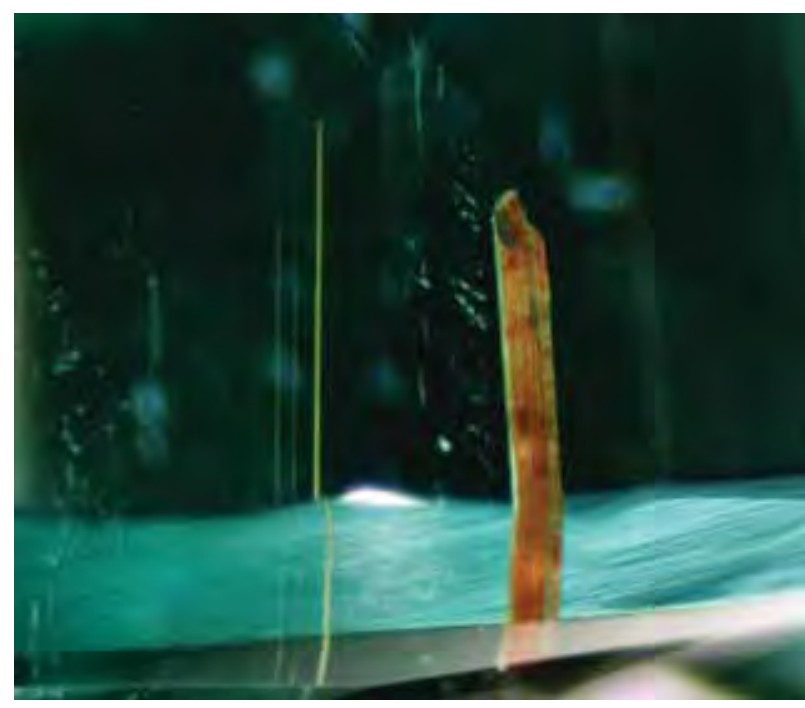

Figure 30. Hollow tubes are quite common in the tourmaline, typically very thin but occasionally much thicker (and flattened), and often stained yellow to red-brown. They occur in paralle orientation in this unheated stone. Photomicrograph by J. C. Zwaan; magnified 36x.

and the thicker tubes, which at first glance might be confused with a mineral inclusion, turned out to be hollow. Many of the tubes were stained yellow to red-brown. Raman analysis identified a finegrained reddish brown substance inside relatively

Figure 31. Minute and slightly larger cracks were common in most of the heated tourmalines, showing both discoid and more elongated shapes. When viewed with darkfield illumination, they often appear as milky stress fractures or otherwise translucent areas. Photomicrograph by J. C. Zwaan; magnified 16x.

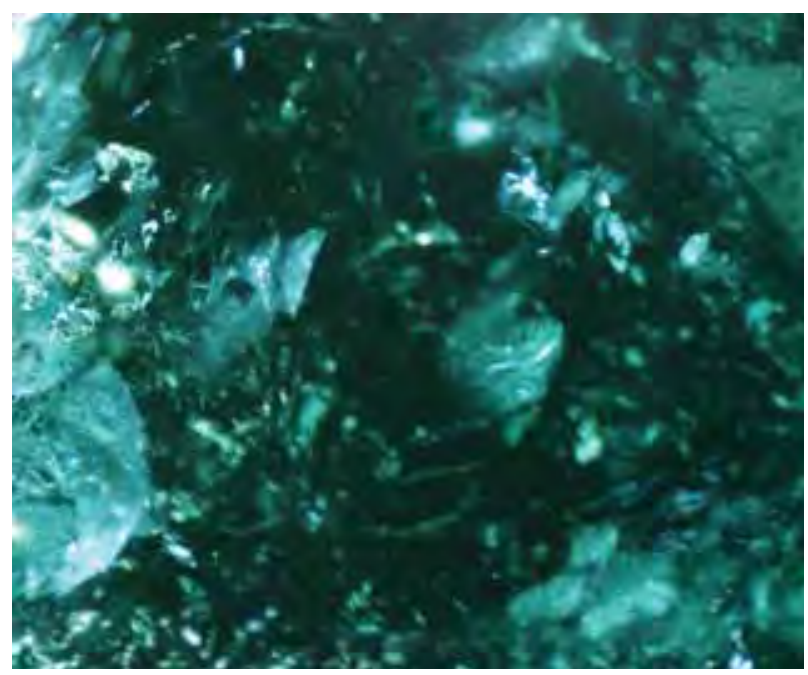

thick tubes in three stones as hematite (again, see figure 30).

M ost of the unheated stones, regardless of how heavily they were included, did not contain many fractures. Only two of the polished rough fragments and one faceted stone were heavily fractured.

Although most of the above features occurred in both unheated and heated stones, some different characteristics were seen in the latter material. A bundant minute cracks were present in all but one (which was only slightly included) heated stone examined (figure 31). These minor cracks were usually small and often discoid, al though more el ongated cracks al so occurred. When viewed with darkfield illumination, they appeared as milky and translucent stress fractures, which became reflective when viewed along the fracture plane. In brightfield or transmitted light they were often invisible, or showed a brownish tinge when viewed along the fracture plane.

In heat-treated stones, the larger voids in partially heal ed fissures often appeared somewhat frosty (especially close to the surface), as if they had dried out during the heating process (figure 32). This is supported by the fact that no bubbles could be detected in them. In one unheated/heated sample pair, the untreated part had irregular cavities filled with liquid (figure 33, left), whereas the treated half had cavities

Figure 32. In the heat-treated tourmal ines, the larger cavities in partially healed fissures often appeared somewhat frosty, which indicates that the fluid dried out during the heating process. Photomicrograph by J. C. Zwaan; magnified 40×.

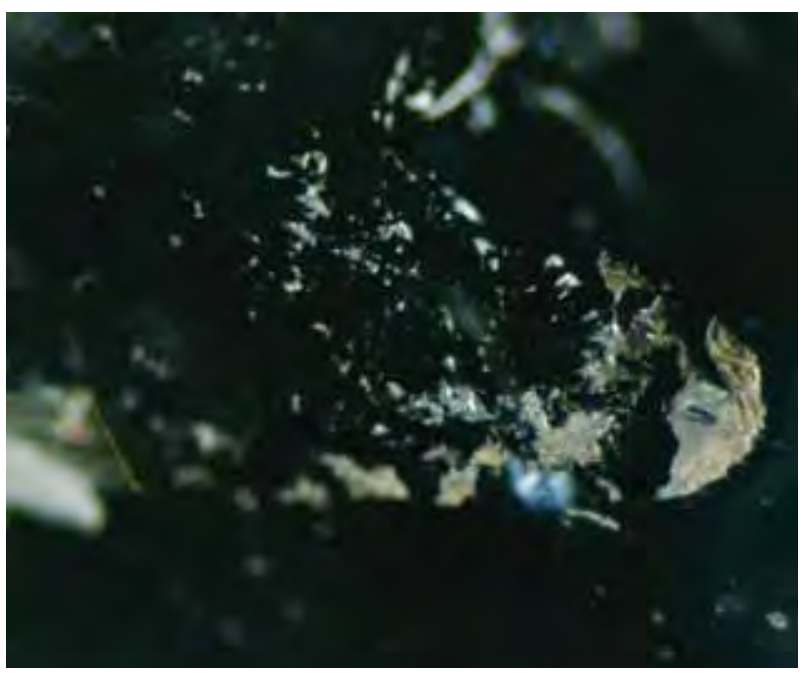



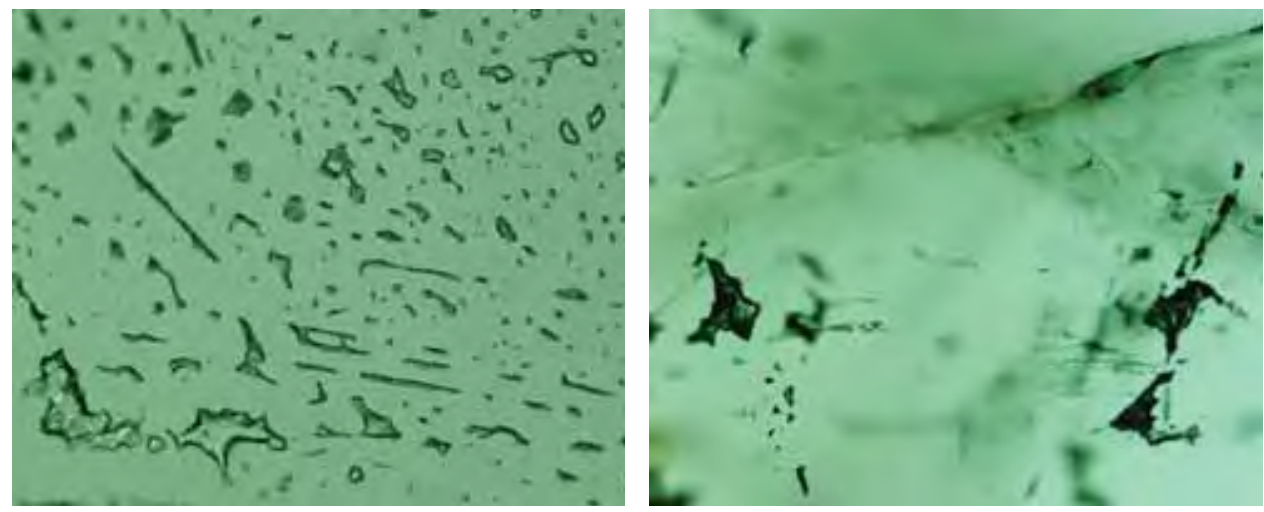

Figure 33. The unheated portion of one tourmaline slice (left) contains irregular-shaped cavities filled with liquid. However, in the portion subjected to heat treatment (right), the cavities appear dark in transmitted light, which indicates that they are empty. Photomicrographs by J. C. Zwaan; magnified $100 \times$.

with the same shape that appeared dark in transmitted light, and were therefore empty (figure 33, right). Some of the smaller fluid inclusions survived the relatively low-temperature heat treatment.

Mineral Inclusions. Small, mostly rounded to subangular, transparent grains of quartz were identified in five of the samples by a combination of optical means and Raman analysis. Quartz occurred as isolated grains (figure 34), but also connected to-and captured within-fluid inclusions.

Flakes of lepidolite were identified by Raman analysis in six tourmal ines (figure 35); in two instances they formed "booklets." In all cases, Raman analysis gave a perfect fit with reference spectra for lepidolite, but also a good fit with polylithionite. As lepidolite, once considered a dis-

Figure 34. The isolated transparent crystal on the left, cl ose to a partially heal ed fissure in a heat-treated tourmaline, was identified as quartz. Photomicrograph by J. C. Zwaan; magnified 50x.

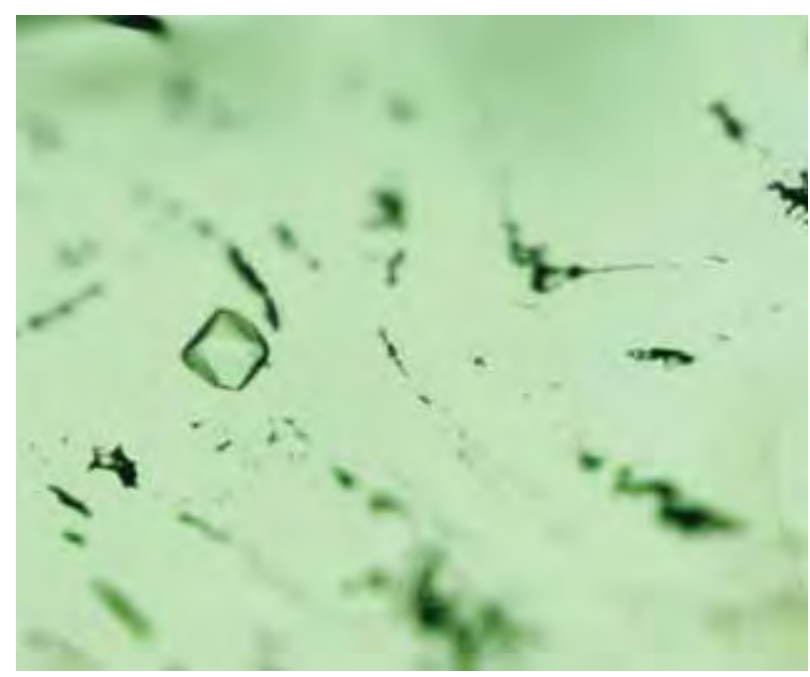

tinct mineral, has been redefined as a lithium-bearing mica in the polylithionite-trilithionite series (Kogure and Bunno, 2004; Brigatti et al., 2005), lepidolite seems an appropriate general name for these inclusions.

A few transparent, irregular-to-rounded grains in an otherwise clean yellowish green tourmaline were identified by Raman analysis as sodic plagioclase (figure 36). The spectra showed a close resemblance to those of both oligoclase and al bite, with two grains showing the best fit for al bite (see, e.g., Mernagh, 1991).

In one very clean green tourmaline, small grains with very low relief, hardly visible with a loupe, appeared to form a trail through the stone. The grains were too deep and too small for Raman analysis; they were tentatively identified as tourmaline, based on their low relief and moderate pleochroism, which was shown clearly by one crystal located somewhat closer to the surface.

Figure 35. Flakes of lepi dol ite were occasionally encountered, as seen in this unheated tourmal ine (left). In contrast to quartz, these flakes show highorder interference colors when viewed with crossed polarizing filters (right). Photomi crographs by J. C. Zwaan; magnified $50 \times$.
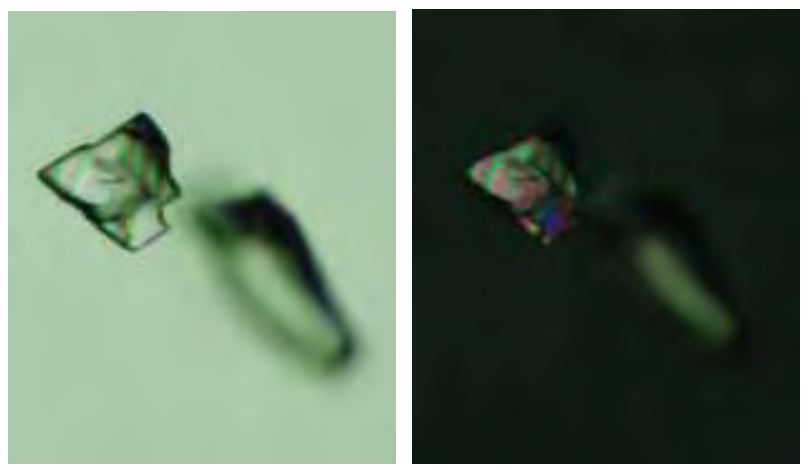


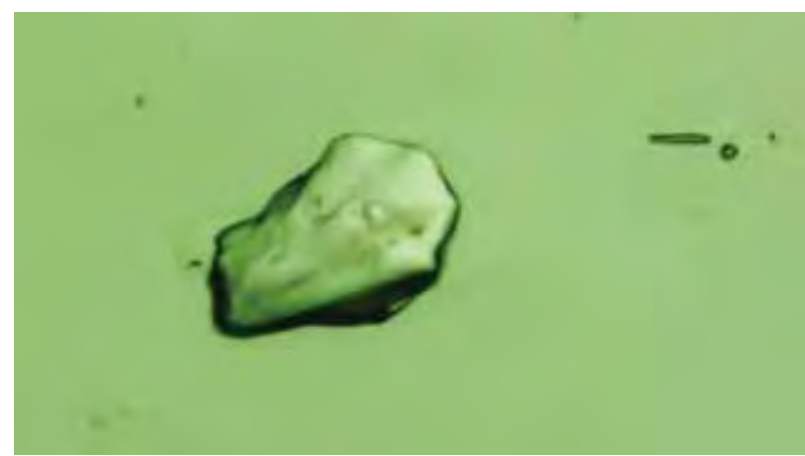

Figure 36. Rounded and irregularly shaped sodic plagioclase crystals, probably al bite, were found in only one yellowish green (unheated) sample, and are therefore considered a rare inclusion in tourmaline from Mavuco. Photomicrograph by J. C. Zwaan; magnified 50x.

\section{CHEMICAL COMPOSTION}

Table 2 presents average chemical analyses for representative samples of the various colors of the tourmal ine; a complete listing of all analyses is avai lable in the G\& G Data Depository. For table 2, we selected the most appropriate analytical technique for each element reported, whereas all data obtained from both techniques are provided in the G\& G Data Depository. Chemical analysis indicated that all the tourmalines were elbaite with $\mathrm{CuO}$ and $\mathrm{MnO}$ concentrations ranging up to 0.66 wt.\% (LA-ICP-MS) and 3.09 wt.\% (microprobe), respectively. The most abundant trace elements were Bi (extremely vari-

TABLE 2. Average chemical composition of representative unheated Cu-bearing tourmalines from Mozambique. ${ }^{a}$

\begin{tabular}{|c|c|c|c|c|c|c|c|}
\hline $\begin{array}{l}\text { Chemical } \\
\text { composition }\end{array}$ & $\begin{array}{c}\text { Pink } \\
\text { (no. 511-7) }\end{array}$ & $\begin{array}{l}\text { Purple } \\
\text { (no. 5u) }\end{array}$ & $\begin{array}{l}\text { Violet }^{b} \\
\text { (no. 1u) }\end{array}$ & $\begin{array}{c}\text { Greenish } \\
\text { blue } \\
\text { (no. 510-6) }\end{array}$ & $\begin{array}{c}\text { Bluish } \\
\text { green } \\
\text { (no. 510-3) }\end{array}$ & $\begin{array}{c}\text { Green } \\
\text { (no. 511-5) }\end{array}$ & $\begin{array}{c}\text { Yellowish } \\
\text { greenc } \\
\text { (no. 17u) }\end{array}$ \\
\hline \multicolumn{8}{|l|}{ Oxide (wt.\%) } \\
\hline $\mathrm{SiO}_{2}$ & 36.59 & 36.68 & 36.64 & 36.68 & 36.62 & 36.63 & 36.71 \\
\hline $\mathrm{B}_{2} \mathrm{O}_{3}$ calc. & 10.97 & 10.90 & 10.88 & 10.97 & 10.97 & 10.96 & 10.95 \\
\hline $\mathrm{Al}_{2} \mathrm{O}_{3}$ & 42.27 & 41.23 & 40.81 & 42.20 & 42.19 & 41.97 & 41.95 \\
\hline $\mathrm{MnO}$ & 0.26 & 2.20 & 2.55 & 0.41 & 0.01 & 0.92 & 1.28 \\
\hline $\mathrm{CuO}$ & 0.07 & 0.16 & 0.11 & 0.30 & 0.54 & 0.54 & 0.21 \\
\hline $\mathrm{CaO}$ & 0.10 & 0.01 & 0.02 & 0.16 & 0.92 & 0.12 & 0.00 \\
\hline $\mathrm{Li}_{2} \mathrm{O}$ calc. & 1.98 & 1.70 & 1.71 & 1.94 & 2.04 & 1.90 & 1.81 \\
\hline $\mathrm{Na}_{2} \mathrm{O}$ & 2.39 & 2.10 & 2.26 & 2.21 & 1.63 & 2.30 & 2.15 \\
\hline $\mathrm{H}_{2} \mathrm{O}$ calc. & 3.23 & 3.32 & 3.32 & 3.24 & 3.28 & 3.23 & 3.33 \\
\hline $\mathrm{F}$ & 1.18 & 0.93 & 0.91 & 1.16 & 1.05 & 1.16 & 0.94 \\
\hline \multicolumn{8}{|c|}{ Trace elements (ppm) } \\
\hline $\mathrm{Be}$ & 6.8 & 3.7 & 5.2 & 6.6 & 96.2 & 79.5 & 4.9 \\
\hline $\mathrm{Mg}$ & 6.6 & 1.0 & $b d l$ & 1.4 & bdl & 10.7 & 3.6 \\
\hline K & 175 & 105 & 46.0 & 191 & 76.3 & 209 & 171 \\
\hline $\mathrm{Ti}$ & 122 & 61.4 & 19.7 & 38.9 & 15.0 & 356 & 292 \\
\hline V & 0.3 & 1.0 & 0.7 & 0.7 & 0.7 & 1.3 & 2.2 \\
\hline $\mathrm{Cr}$ & 8.8 & 3.5 & bdl & 4.8 & 4.2 & 8.2 & 3.0 \\
\hline $\mathrm{Fe}$ & bdl & 53.1 & bdl & bdl & bdl & 5775 & 895 \\
\hline $\mathrm{Ni}$ & 0.6 & 3.7 & 1.1 & 0.3 & bdl & 0.3 & 0.9 \\
\hline $\mathrm{Zn}$ & 1.4 & 2.5 & 0.6 & 1.4 & 0.6 & 188 & 30.0 \\
\hline $\mathrm{Ga}$ & 617 & 335 & 312 & 517 & 624 & 247 & 380 \\
\hline $\mathrm{Ge}$ & 4.6 & 4.8 & 4.6 & 5.9 & 6.8 & 20.8 & 8.1 \\
\hline $\mathrm{Nb}$ & 1.4 & 0.8 & 0.7 & 1.4 & bdl & bdl & 0.5 \\
\hline Mo & bdl & 0.9 & bdl & 0.7 & bdl & 1.0 & 2.4 \\
\hline $\mathrm{Sn}$ & 12.1 & 4.0 & 1.3 & 4.0 & 0.3 & 3.3 & 6.4 \\
\hline $\mathrm{Ta}$ & bdl & bdl & bdl & 0.7 & 0.6 & bdl & bdl \\
\hline $\mathrm{Pb}$ & 10.0 & 5.7 & 6.7 & 10.4 & 292 & 128 & 8.8 \\
\hline $\mathrm{Bi}$ & 38.4 & 24.3 & 209 & 61.3 & 3445 & 3163 & 53.2 \\
\hline
\end{tabular}

${ }^{a}$ Analyses of oxides by electron microprobe (except for $\mathrm{CuO}$, analyzed by LA-ICP-MS); average of $4-5$ analyses per sample. For complete electron-microprobe analyses, including the calculated ions per formula unit, see the G\&G Data Depository. Analyses of trace elements by LA-ICP-MS; average of two analyses per sample (not in same locations as the oxide analysis points). Abbreviation: bdl = below detection limit.

${ }^{b}$ This is the unheated sample (no. 1) used for the absorption spectrum in figure 39 (top).

'This is the unheated sample (no. 17) used for the absorption spectrum in figure 39 (bottom). 
able, exceptional ly up to 9,286 ppm), Fe (up to 5,854 ppm), Ga (up to 674 ppm), Zn (up to 512 ppm), and $\mathrm{Ti}$ (up to $497 \mathrm{ppm}$ ). While significant amounts of Fe were present in the green stones, the other colors contained extremely low amounts in most cases (i.e., below the detection limit of the instrument, $-40 \mathrm{ppm}$ ). Another important tourmaline chromophore, Ti, was al so depl eted in those colors.

As expected, no consistent differences were noted in the composition of the sample pairs before and after heating (since the heating affects the oxi dation state of the chromophoric elements, not their concentration). Some minor variations between pieces from a single slice occurred, but these were most likely due to inherent heterogeneity. Differences in color between samples, however, were accompanied by distinct variations in composition. In general, unheated viol et stones (and their heated "neon" blue counterparts) contained noticeably lower concentrations of $\mathrm{Ti}, \mathrm{Fe}$, and $\mathrm{Zn}$-and higher concentrations of $\mathrm{Bi}$-than all the green samples. Ranges in the concentrations of $\mathrm{Mn}, \mathrm{Cu}, \mathrm{Ga}$, and $\mathrm{Pb}$ were relatively similar for stones of both the violet and green colors.

$M$ eaningful trends in the chemical data could be discerned by plotting $\mathrm{Cu}$ vs. Fe+Ti (whereas too much scatter resulted from plotting $M n$ vs. Fe+Ti). The average chemical data for all samples analyzed (both unheated and heated) are shown in figure 37, grouped according to color. M ost of the green samples had distinctly higher contents of Fe+Ti than the other colors. All of the color groups showed considerable overlap in $\mathrm{Cu}$ contents; the lowest $\mathrm{Cu}$ contents were measured in some of the pink to pinkish purple samples.

Figure 38 plots the same elements for only the before-and-after heated sample pairs (again, see figure 22) according to their color. As expected, samples before and after heating commonly exhibit differences in composition due to preexisting chemical heterogeneity. Although it is not possible to clearly indicate specific sample pairs on this diagram, average chemical analyses of all samples are available in the G\&G Data Depository. The green to yellow-green samples had the highest Fe+Ti contents and did not show appreciable changes in color with heating. The blueto bluish green tourmalines contained less Fe+Ti; heating of those samples made the original hues greener or more intense. The violetish blue to purple samples had the lowest Fe+Ti values and showed the greatest change with heating, becoming blue to bluish green.

\section{UV-VISNIR SPECTROSCOPY}

Figure 39 shows the Vis-N IR absorption spectra for two pairs of polished slabs, before and after heating. The chemical analyses of these samples (before

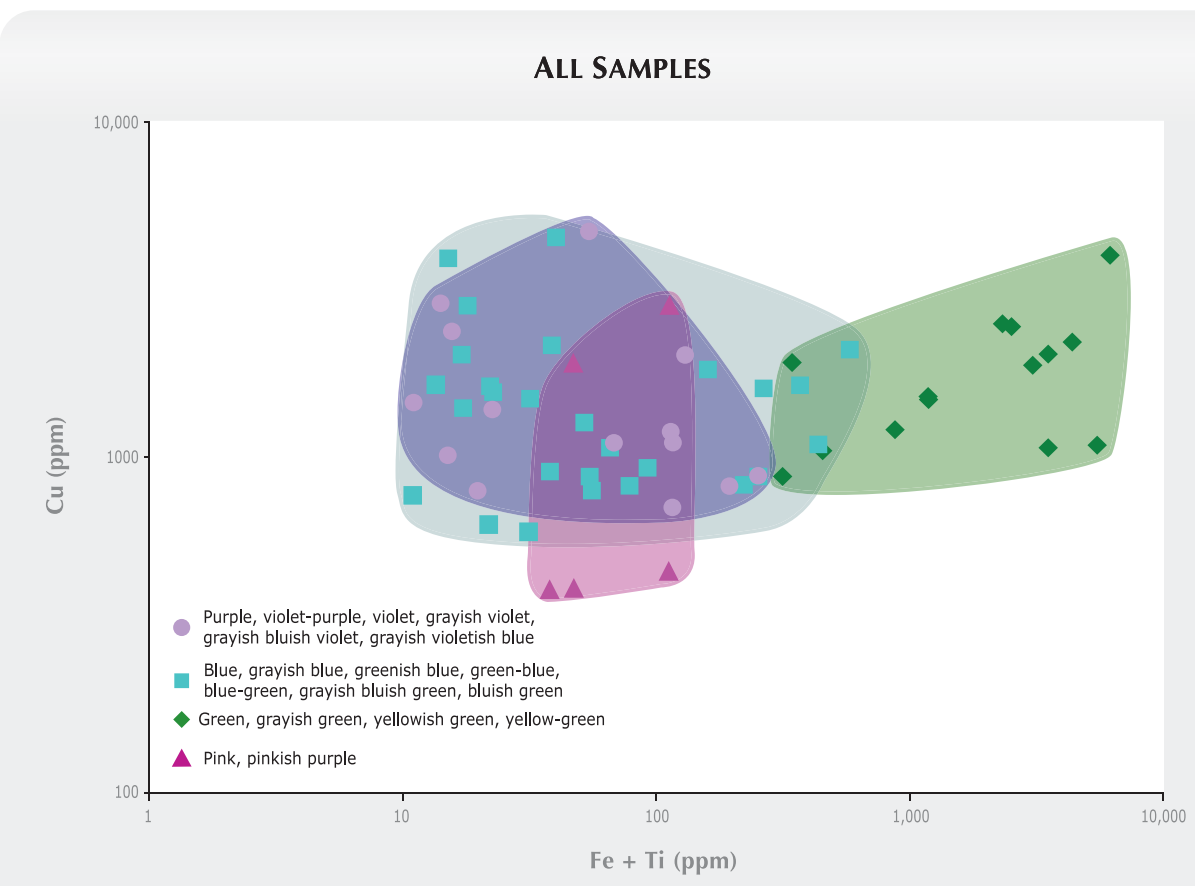

Figure 37. This pl ot of $\mathrm{Cu}$ vs. Fe+Ti shows the average chemical data for all tourmal ine samples analyzed in this study, according to the four main color groups. Due to large variations in composition, both axes use a logarithmic scale. The green to yellowish green samples have the highest Fe+Ti contents, and therefore would not be expected to change color with heat treatment. Some of the pink to reddish purple samples also would not be expected to change to the "neon" green or blue colors due to their low Cu contents. 


\section{BEFORE-AND-AFTER HEATED SAMPLES}

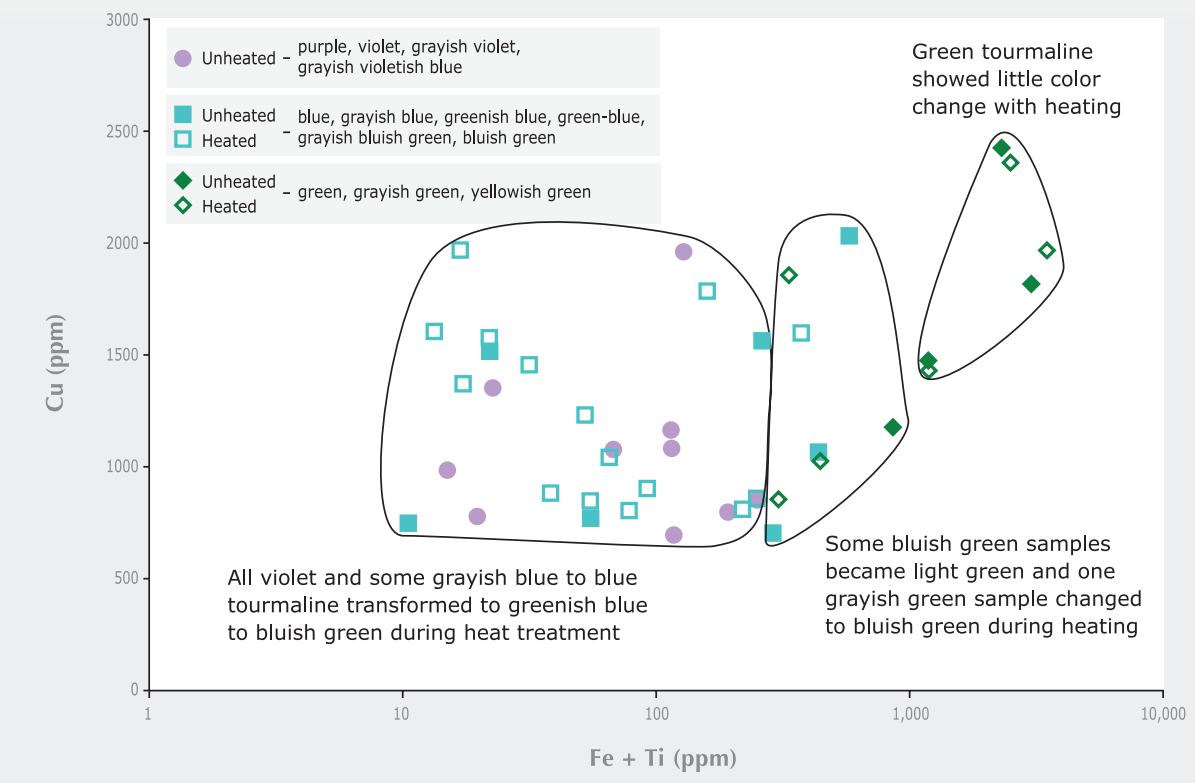

Figure 38. The same elements plotted in figure 37 are shown again here, for only the tourmaline pairs before and after heat treatment that shared the same piece of rough (see figure 22). Since this sample set has less variation in $\mathrm{Cu}$ content (because it is smaller), a logarithmic scale is not necessary for theY-axis. The samples with the highest Fe+Ti contents (green to yell owish green) did not change color, whereas the others became blue to bluish green (or, in the case of those that were originally blue to green, became more intense) with heating. heating) are provided in table 2. All the samples showed two distinctive broad bands centered at $\sim 700$ and $-900 \mathrm{~nm}$, caused by $\mathrm{Cu}^{2+}$ absorption (A bduriyim et al., 2006). In addition, the unheated, violet-colored tourmalines also exhibited a broad absorption between -500 and $-550 \mathrm{~nm}$ due to $\mathrm{Mn}^{3+}$, causing a transmission window at $-400-430 \mathrm{~nm}$ that produced the violet color. This band was very weak or absent in both the unheated and heated "neon" blue samples, as well as in most of the green stones. In addition to the $\mathrm{Cu}^{2+}$ absorption bands, many of the green tourmalines (both heated and unheated) showed small peaks at $-415 \mathrm{~nm}$ and a broad band at $\sim 325 \mathrm{~nm}$, which Rossman and Mattson (1986) attributed to $\mathrm{Mn}^{2+}$ and $\mathrm{Mn}^{2+}-\mathrm{Ti}^{4+}$ intervalence charge transfer (IVCT), respectively.

Reduction of the $\mathrm{Mn}^{3+}$ absorption band was the major change noted as the result of heating of the violet and darker blue tourmal ine samples (see, e.g., figure 39, top). Most of the green samples showed little change in Vis-NIR absorption after heating (see, e.g., figure 39, bottom).

Spectra for various natural-color faceted Cu-bearing tourmalines from Mozambique are shown in figure 40.

\section{DISCUSSION}

Gemological Properties. Wentzell (2004), Wentzell et al. (2005), and Liu and Fry (2006) documented a "reverse" color change in Cu-bearing tourmaline from Mozambique. Unlike the usual al exandrite effect, these "reverse" stones showed warm coloration in daylight (purple) and cool colors (gray-bluish green to greenish blue) in incandescent light. However, many of our samples appeared violetish blue to pale blue in daylight and greenish gray to grayish green in incandescent light. Thus, those samples were not changing from warm to cool colors, but rather from "cool" to "less cool" colors-which, in principal, is the same mechanism as in al exandrite. It is interesting to note that the purple tourmalines we studied shifted color in the normal direction, from purple to purplish pink/red.

The measured RI and SG values (table 1) show a slightly wider range than the values for M ozambique $\mathrm{Cu}$-bearing tourmaline presented by Milisenda et al. (2006) and A bduriyim et al. (2006), with significantly higher refractive indices for the green tourmalines, and lower overall specific gravity values for the blue-to-violet and bluish green tourmalines. While our M ozambique samples generally showed overlapping values with $\mathrm{Cu}$-bearing tourmalines from other localities, blue to blue-green and yellowish green to green material from Mina da Batal ha, Brazil, may show slightly higher SG values, up to 3.11 and 3.12, respectively (Fritsch et al., 1990; A bduriyim et al., 2006). One blue-green stone from that mine 
showed some different properties: birefringence of 0.025 , and a specific gravity of 3.12. The values of the light blue $\mathrm{Cu}$-bearing tourmalines from the Alto dos Quintos mine in Brazil show complete overlap, whereas the (light) blue to bluish green stones from the Mulungu mine in Brazil show higher SG values (3.08-3.13: Shigley et al., 2001; Abduriyim et al., 2006). Violetish blue and blue to bluish green $\mathrm{Cu}$-bearing tourmalines from $\mathrm{N}$ igeria exhibit consi derable overlap (see Smith et al., 2001; A bduriyim et al., 2006), but may have SG values up to 3.10. The similarity in properties between $\mathrm{Cu}$-bearing tourmaline from the various

Figure 39. Vis-NIR absorption spectra are shown for two pairs of polished tourmalineslabs, before and after heating. In the top spectra, the reduction of the $\mathrm{Mn}^{3+}$ absorption with heating (in the absence of significant Ti- and Ferelated absorptions) results in a dramatic change from violet to blue-green. In the bottom spectra, the yell owish green color changed very little due to strong $\mathrm{Mn}^{2+}-\mathrm{Ti}^{4+}$ absorption. The spectra have not been offset vertically. Sample thicknesses: 3.36 and $3.80 \mathrm{~mm}$ (unheated and heated, top) and 1.42 and $1.85 \mathrm{~mm}$ (unheated and heated, bottom). Inset photos by C. D. Mengason.

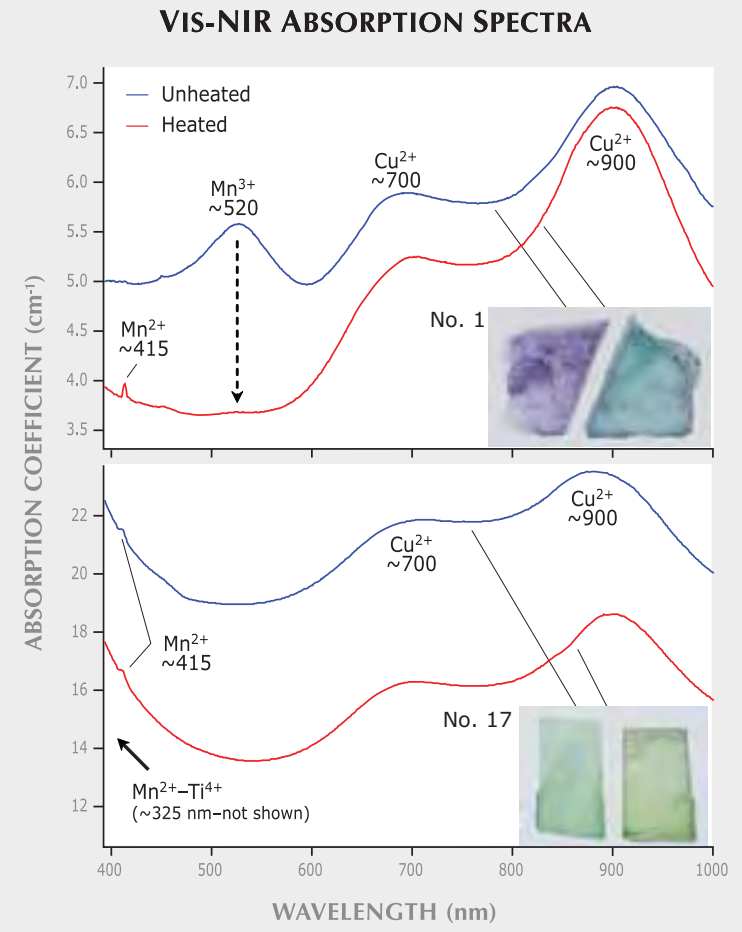

localities, and the initial difficulty in separating them, contributed to the desire by some in the trade to refer to all of these tourmalines by the trade name "Paraíba" (see box A).

This is the first detailed description of inclusions in copper-bearing tourmaline from M ozambique. Abduriyim et al. (2006) mentioned the presence of liquid inclusions, two-phase (liquid-gas) inclusions, and healed fractures, while Milisenda et al. (2006) mentioned trichites and the presence of hollow tubes, generally filled with a brownish substance. The statement made by Abduriyim et al . (2006) that in faceted stones these tubes may be indicative of tourmalines from Nigeria (because they are not common in Mozambique stones) is not supported by this study. Of 47 faceted tourmalines studied, 29 contained hollow tubes (i.e., a majority of the stones, nearly $62 \%$ ).

Lepidolite, quartz, and feldspar have not been reported as mineral inclusions in Cu-bearing tourmaline from Brazil or Nigeria (e.g., Fritsch et al., 1990; Shigley et al., 2001), although Abduriyim et al. (2006) did report "hexagonal mica platelets" in $\mathrm{Cu}$-bearing tourmaline from $\mathrm{N}$ igeria. In any case, these minerals should probably not be considered local ity-specific inclusions, since they have been encountered in el baite from many different sources (see, e.g., Koivula, 2005). Consistent with the findings of Milisenda et al. (2006), we did not see any copper platelets in our samples, as were documented in Brazilian material by Brandstätter and N iedermayr (1994).

A bundant minute cracks were obvious in al most $90 \%$ of the heat-treated stones but in only a few of the unheated samples; they were probably caused by stress released during heating. The larger fluid inclusions, or the ones closer or connected to the surface, were the least stable to heating and therefore most prone to leakage and decrepitation, which may explain their "frosty" appearance when viewed with darkfield illumination. These features, together with the minute cracks that al ways accompanied them, were seen in more than $20 \%$ of the heated stones and in none of the unheated stones, so they are good indicators of heat treatment. Only one heated stone did not show either of these features. In addition, a faint blue fluorescence to long-wave UV may be indicative of heat treatment, al though it was not visible in all heat-treated stones (table 1) or in any of the samples examined by Milisenda et al. (2006). All but two of the unheated stones we examined were inert to $U V$ radiation. 


\section{UV-VIS-NIR ABSORPTION SPECTRA}
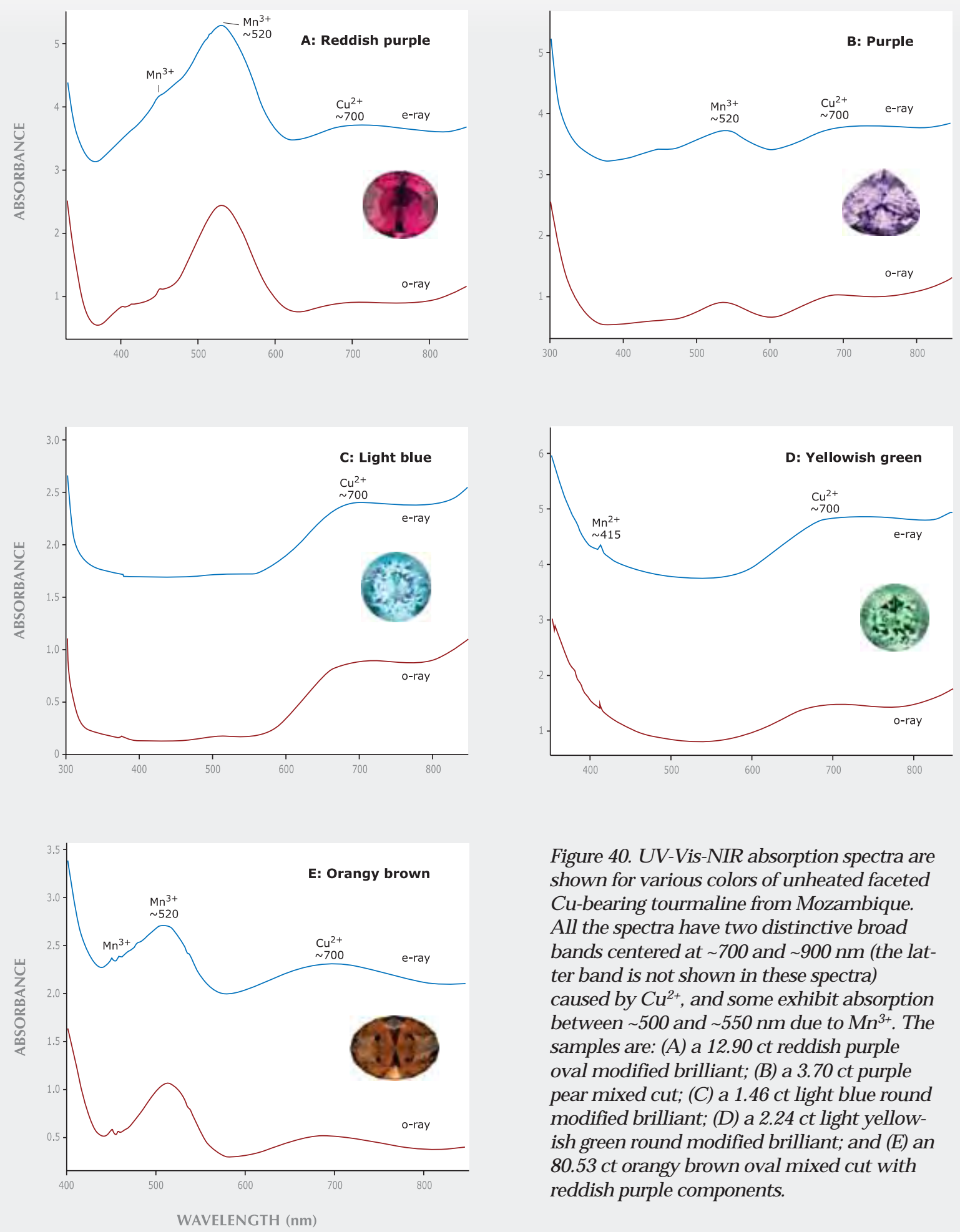

Figure 40. UV-Vis-NIR absorption spectra are shown for various col ors of unheated faceted Cu-bearing tourmaline from Mozambique. All the spectra have two distinctive broad bands centered at $\sim 700$ and $-900 \mathrm{~nm}$ (the latter band is not shown in these spectra) caused by $\mathrm{Cu}^{2+}$, and some exhibit absorption between -500 and $-550 \mathrm{~nm}$ due to $\mathrm{Mn}^{3+}$. The samples are: (A) a 12.90 ct reddish purple oval modified brilliant; (B) a 3.70 ct purple pear mixed cut; (C) a 1.46 ct light blue round modified brilliant; (D) a 2.24 ct light yellowish green round modified brilliant; and (E) an 80.53 ct orangy brown oval mixed cut with reddish purple components. 


\section{BOX A: NOMENCLATURE ISSUES}

"Paraíba tourmaline" is a trade name that was originally used to describe brightly colored blueto-green $\mathrm{Cu}$ - and $\mathrm{Mn}$-bearing el baite from M ina da Batal ha in Paraíba State, Brazil. After similar tourmalines were found in other areas of Brazil (Rio Grande do N orte State), as well as in N igeria and Mozambique, gem laboratories were asked to identify material from the various sources for their clients. Initially, using semiquantitative EDXRF chemical analysis, the laboratories were not able to separate the localities. Further research quantifying the trace elements using LAICP-MS has produced a reliable technique for distinguishing nearly all $\mathrm{Cu}$-bearing tourmalines from Brazil, N igeria, and M ozambique.

The trade, however, had become accustomed to calling the "neon" blue-to-green tourmalines "Paraíba" regardl ess of their origin. In January 2007, the Laboratory Manual Harmonization Committee (consisting of representatives from the AGTA Gemological Testing Center-U.S., CISGEM - Italy, GAAJ Laboratory-Japan, GIA Laboratory-U.S., GIT Gem Testing Laboratory-Thailand, Gübelin Gem Lab and SSEF Swiss Gemmological InstituteSwitzerland) published LMHC Information Sheet no. 6 , which defines Paraíba tourmal ine as

a blue (electric blue, neon blue, violet blue), bluish green to greenish blue or green el baite tourmaline, of medium to high saturation and tone, mainly due to the presence of $\mathrm{Cu}$ and $\mathrm{Mn}$ of whatever geographical origin. The name of the tourmaline variety 'Paraíba' is derived from the Brazilian locality where this gemstone was first mined.

Two wording options are provided-one where the report uses "Paraíba" as a variety designation, and one where it is used as a trade name. M ost member labs of LM HC have opted to use "Paraíba" as a trade name.
One consequence of the above decision (which is different from what the LMHC decided earlier in 2006, when they did not define saturation and tone; compare A bduriyim et al., 2006) is that certain colors that were part of the original Paraíba output were excluded, notably violet to reddish purple and yellowish green. Although violet stones can often be heat-treated to produce the blue-to-green varieties, an awkward situation has arisen in which $\mathrm{Cu}$ - and $\mathrm{Mn}$ bearing el baite of this col or may get a country-of-origin designation of Brazil, and still not be considered a Paraíba tourmaline.

A nother nomencl ature issue concerns the saturation and tone of the blue-to-green color that is necessary for the "Paraíba" trade name. This issue became particularly important with the availability of significant amounts of Mozambique Cu-bearing tourmalines showing either desaturated or light to very light colors, particularly after being cut into smaller sizes. The saturation necessary for a bluetogreen $\mathrm{Cu}$-bearing tourmaline to be considered "Paraíba" does not have widespread agreement. At the time this article was prepared, the LMHC was working on a consistent definition for these saturation levels. M eanwhile, some deal ers have bypassed the problems related to both geographic origin and coloration by referring to the material as cuprian tourmaline.

In cases where a stone does not have sufficient saturation, is too light in tone, or is not considered the proper hue to be called "Paraíba," some labs will issue a report indicating that it is a $\mathrm{Cu}$ - and $\mathrm{Mn}$-bearing tourmaline. There is no universal agreement on the level of copper (and manganese) necessary for a tourmal ine to be considered "Cu- and Mn-bearing," and given the increase in sensitivity of modern ana lytical techniques such as LA-ICP-MS, such criteria should be carefully reviewed for consistency between laboratories.
Chemical Composition and UV-Vis-NIR Spectroscopy. The Paraíbatype tourmalines from M ozambique are characterized by low Fe and Ti concentrations and relatively low-to-moderate amounts of $\mathrm{Cu}$. As outlined below, their attractive coloration is due to a combination of these chemical features. Overall, the composition of our samples is comparable with the data presented by Milisenda et al . (2006), but we mear sured lower values for $\mathrm{Cu}$ and $\mathrm{Mn}$ than were reported by Abduriyim et al. (2006). N ote that anomal ously higher copper values of 2.08-3.21 wt.\% CuO were measured by Abduriyim et al. (2006) in only a few highly saturated greenish blue to bluish green samples from M ozambique; they are not representative of the typical tourmaline composition (A. Abduriyim, pers. comm., 2008). Consistent with data previously 
recorded by LA-ICP-MS at GIA (248 analyses on 122 samples; unpublished GIA data), all the samples analyzed for this study fell within the following ranges: $0.05-0.66$ wt.\% CuO, 0.01-3.09 wt.\% M nO, 10-497 ppm Ti, and from below detection limit to 5854 ppm Fe.

The coloration of M ozambique Cu-bearing tourmaline is controlled, for the most part, by a combination of the concentrations and oxidation states of $\mathrm{Cu}, \mathrm{Mn}, \mathrm{Fe}$, and Ti (Wentzell et al., 2005; Abduriyim et al ., 2006; M ilisenda et al., 2006; Rondeau and Delaunay, 2007). The vast majority of the samples analyzed showed strong $\mathrm{Cu}^{2+}$ absorptions centered at $\sim 700$ and $900 \mathrm{~nm}$, and contained relatively high amounts of $\mathrm{Mn}$. In the absence of significant amounts of $\mathrm{Fe}$ and $\mathrm{Ti}$, and when the manganese occurs as $\mathrm{Mn}^{2+}$, the tourmalines show an attractive "neon" blue color without heating. If, however, the manganese is present as $\mathrm{M} \mathrm{n}^{3+}$ (the more common oxidation state), a strong absorption at $\sim 520 \mathrm{~nm}$ causes the stones to appear violet to pink.

$\mathrm{H}$ eat treatment of $\mathrm{Cu}$ - and $\mathrm{Mn}$-bearing tourmaline has long been known to significantly change the color of many stones. This occurs simply by reducing the oxidation state of $\mathrm{Mn}$ in the stone, from $\mathrm{Mn}^{3+}$ (which causes violet-pink coloration) to $\mathrm{Mn}^{2+}$ (not a strong chromophore in tourmaline), but the resultant color also depends on the amount of Fe and Ti present. Most of the violet M ozambique $\mathrm{Cu}$-bearing tourmal ine contai ns little Fe and $\mathrm{Ti}$. Heat treatment of such material removes the $\mathrm{M} \mathrm{n}^{3+}$ absorption at $-520 \mathrm{~nm}$, creating a transmission window from -400 to $580 \mathrm{~nm}$ that yields a "neon" blue color (figure 39, top). Heat treatment of a similar stone containing significant $\mathrm{Ti}$ and $\mathrm{Fe}$ will produce green coloration due to $\mathrm{Mn}, \mathrm{Ti}$, and $\mathrm{Fe}$, producing broad absorptions at $-325,-420$, and $710 \mathrm{~nm}$. The resulting transmission window at $-550 \mathrm{~nm}$ is responsible for the green color.

Many unheated green samples have substantially more Fe and $\mathrm{Ti}$ than the violet samples, and much of the manganese is al ready in the $\mathrm{Mn}^{2+}$ state. In such material, the $\mathrm{Mn}, \mathrm{Ti}$, and possibly Fe IVCT absorptions are naturally present and combine with the $\mathrm{Cu}^{2+}$ bands to produce a green color. Heating these stones results in little to no color modification, as shown in the bottom of figure 39.

Thus, it should be possible to predict the effects of heat treatment of Cu-bearing tourmalines from M ozambique by measuring their $\mathrm{Ti}$ and Fe concentrations. UV-Vis spectroscopy, which directly reflects the composition, can also be used to predict the response to heating (M ilisenda, 2007).

\section{GEOLOGIC ORIGIN OF CU-BEARING TOURMAUNE ROM MOZAMBIQUE}

The authors' observations of the tourmal ine-bearing layer revealed sedimentary structures and a clastsupported matrix that suggest a fluvial origin (i.e., deposited by a stream or river). The dominance of angular clasts indicates a short transport distance (probably less than $10 \mathrm{~km}$ ) for most of the quartz in the matrix. It also suggests the importance of mechanical weathering and hillsl ope transportation. However, the sub- to well-rounded quartz and tourmaline clasts had longer transport distances and transit times.

The dominance of angular clasts suggests that fluvial transport was spasmodic (i.e., it occurred only occasionally and then for a short time). The rather coarse grain size (10-30 mm) suggests energetically high hydrodynamic conditions. The openworked clast-supported fabric of the gravel layer al so indicates short transport distances and abrupt rapid deposition. Therefore, the sedimentology and internal architecture of the tourmal ine-bearing layer suggest a braided fluvial depositional environment. It is likely that semi-ephemeral to perennial braided streams transported and redistributed al luvial materials down-valley during high discharge events (wet seasons) of relatively short duration.

It can be concluded that the tourmaline-bearing layer is an accretional unit deposited by slope processes and redistributed fluvially. Much of the angular material may be derived from the local simple granitic pegmatites (some aquamarine-bearing) that cross-cut the basement rocks. Also, the angular material may have been derived upstream from the hinterland valleys and transported downhill through spasmodic flash floods (distances on the order of $10 \mathrm{~km}$ or less).

The rounded tourmalines and quartz $(<10 \%)$ were transported longer in terms of both time and distance, and perhaps were redistributed and concentrated several times. Given the known fairly localized occurrence of the Cu-bearing tourmaline in this part of M ozambique, its origin must relate to the catchment area of the fluvial units and to the former presence of pegmatite source rock upstream. Based on the size of the current catchment, we infer that these (sub)rounded clasts represent maximum transport/reworking distances on the order of 100 


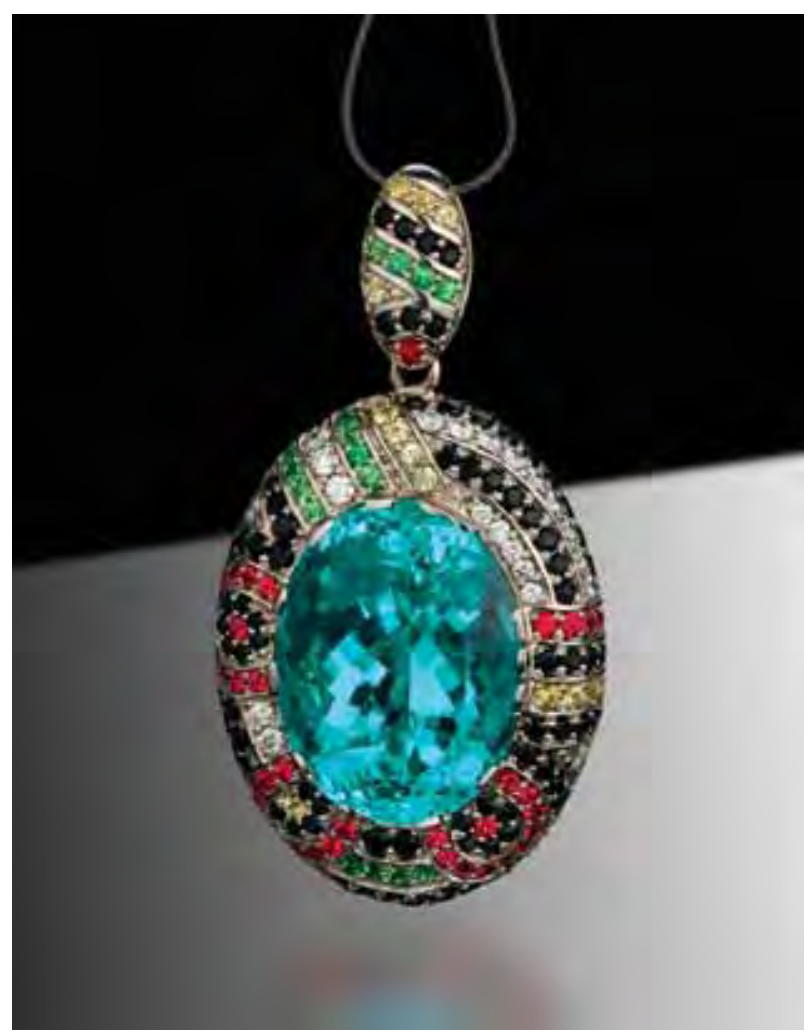

Figure 41. Cu-bearing tourmaline from Mozambique (here, $14.53 \mathrm{ct}$ and heated) is being showcased by innovative jewel ry designs. The 18K white gold pendant is accented by black and red spinel, yellow sapphire, tsavorite, and diamond. Courtesy of Carley McGee-Boehm, Carley Jewels, San Diego, California; photo by Robert and Orasa Weldon.

$\mathrm{km}$. To the northwest, this falls well within the boundaries of the Alto Ligonha pegmatite district (compare with figure 5). However, since no Cu-bearing tourmaline is known from previously worked deposits in that district (primary or alluvial), the materials from Mavuco were apparently derived from pegmatites that were quite unusual compared to those currently known in the area. Also, the transport direction of the sediments depended on the topography, which directly resulted from the regional tectonics/geology of the area at the time that the original pegmatites eroded. The direction that the rivers flow today may not have been the same when the tourmal ine-bearing sediments were eroded and deposited.

The site of tourmaline deposition depended on the local topography and slope direction, and it may be no coincidence that the deposit is located in the area between the granitic hills of Mt. Muli to the south and Mt. Iulùti to the north. This arrangement of the resistant granitic rocks, combined with the regional northeast-southwest structure of the basement, may have created ideal topographic conditions for channeling the sediments derived from the original pegmatites into their present position. In addition, this may have prevented the tourmaline from being dispersed over long distances, even during the reworking that is suggested by their rounded nature.

\section{CONCLUSON}

Copper-bearing tourmal ine from $\mathrm{M}$ ozambique is notable for its variety of bright colors, availability in relatively large quantities, and impressive number of large clean stones. Although most of the material does not attain the saturation of the famous Paraíba tourmal ine from Brazil, the M ozambique deposit has hel ped make Cu-bearing tourmal ine more affordable and also has popularized its use in fine jewelry (figure 41). It is expected that the material will become even more widely available in the near future, as mechanized mining becomes more prevalent. Further exploration could turn up additional reserves in the Mavuco area, particularly through systematic test pitting over a larger area than has currently been mined. Wider-scale exploration throughout the eastern part of the Alto Ligonha pegmatite district may also result in the discovery of new areas for this tourmaline.

\author{
ABOUT THE AUTHORS \\ Mr. Laurs is editor of Gems \& Gemology at GIA in Carlsbad. Dr. \\ Zwaan is director of the Netherlands Gemmological Laboratory, \\ and curator of minerals and gems, at the National Museum of \\ Natural History "Naturalis," Leiden, the Netherlands. Dr. Breeding \\ is research scientist at the GIA Laboratory in Carlsbad. Ms.
}

Beaton and Mr. Befi are staff gemologists at the GIA Laboratory in New York. Dr. Rijsdijk is researcher and sedimentologist at the Netherlands Institute of Applied Geosciences TNO, Delft, the Netherlands. Dr. Simmons is professor of mineralogy and university research professor, and Mr. Falster is senior research technologist, at the University of New Orleans, Louisiana. 


\section{ACKNOWLEDGMENTS}

The authors are grateful to Moses Konate, Salifou Konate, and Chirindza Henrique (Mozambique Gems, Nampula) for providing logistical support in the field and access to the mining property, as well as supplying information and donating samples for research. They also appreciate the cooperation and assistance of company partners Saint Clair Fonseca J r., Daniel Trinchillo, Burkhard Pohl, and Marcus Budil. Additional samples were loaned or donated by Bill Barker (Barker \& Co., Scottsdale,
Arizona), Bill Larson (Pala International, Fallbrook, California), and Robert Kane (Fine Gems International, Helena, Montana). Dirk van der Marel (National Museum of Natural History "Naturalis," Leiden) is thanked for preparing maps and for general assistance. Access to Raman facilities was provided to one of the authors ( $\mathrm{CZ}$ ) by the CCIP French Gemmological Laboratory, Paris. We also thank Farooq Hashmi (Intimate Gems, J amaica, New York) for providing helpful information and discussions after his 2006 trip to the mining area.

\section{REFRENCES}

Abduriyim A., Kitawaki H. (2005) Cu- and M n-bearing tourmaline: More production from Mozambique. Gems \& Gemology, Vol. 41, N o. 4, pp. 360-361.

Abduriyim A., Kitawaki H., Furuya M., Schwarz D. (2006) "Paraíba"-type copper-bearing tourmaline from Brazil, Nigeria, and M ozambique: Chemical fingerprinting by LA-ICP-MS. Gems \& Gemology, Vol. 42, No. 1, pp. 4-21.

Bettencourt Dias M., Wilson W.E. (2000) Famous mineral localities: The Alto Ligonha pegmatites, M ozambique. Mineral ogical Record, Vol. 31, pp. 459-497.

Brandstätter F., N iedermayr G. (1994) Copper and tenorite inclusions in cuprian-elbaite tourmaline from Paraíba, Brazil. Gems \& Gemology, Vol. 30, No. 3, pp. 178-183.

Breeding C.M., Rockwell K., Laurs B.M. (2007) Gem N ews International: New Cu-bearing tourmaline from Nigeria. Gems \& Gemology, Vol. 43, No. 4, pp. 384-385.

Brigatti M.F., Caprilli E., Malferrari D., Medici L., Poppi L. (2005) Crystal structure and chemistry of trilithionite-2M 2 and polylithionite-2M2. European Journal of Mineralogy, Vol. 17, No. 3, pp. 475-481.

Deer W.A., Howie R.A., Zussman J. (1994) An Introduction to the Rock Forming Minerals. Longman Group, London, 528 pp.

Fritsch E., Shigley J.E., Rossman G.R., Mercer M.E., M uhlmeister S., Moon M. (1990) Gem-quality cuprian-el baite tourmalines from São José da Batalha, Paraíba, Brazil. Gems \& Gemology، Vol. 26, No. 3, pp. 189-205.

Furuya M., Furuya M. (2007) Paraíba Tourmaline-Electric Blue Brilliance Burnt into Our Minds. Japan Germany Gemmological Laboratory, Kofu, Japan, 24 pp.

Gübelin E.J., Koivula J.I. (2005) Photoatlas of Inclusions in Gemstones, Vol. 2. Opinio Publishers, Basel, Switzerland, 829 pp.

Kogure T., Bunno M. (2004) Investigation of polytypes in lepidolite using electron back-scattered diffraction. American Mineralogist, Vol. 89, pp. 1680-1684.

Koivula J.I., Kammerling R.C., Eds. (1989) Gem N ews: Unusual tourmalines from Brazil. Gems \& Gemology, Vol. 25, No. 3, pp. 181-182.

Lächelt S. (2004) The Geology and Mineral Resources of Mozambique. N ational Directorate of Geology, Maputo, Mozambique, $515 \mathrm{pp}$.

Liu Y., Fry B.A. (2006) A colorimetric study of a tourmaline from Mozambique which shows a reverse al exandrite effect. Journal of Gemmology, Vol. 30, N o. 3/4, pp. 201-206.

Mernagh T.P. (1991) Use of the laser Raman microprobe for discrimination amongst feldspar minerals. Journal of Raman Spectroscopy, Vol. 22, N o. 8, pp. 453-457.

Milisenda C.C. (2005) A new source of cuprian tourmalines. Gemmologie: Zeitschrift der Deutschen Gemmologischen Gesellschaft, Vol. 54, N o. 2-3, pp. 63-64.

Milisenda C.C. (2007) Paraiba tourmaline revisited. 30th
International Gemmological Conference, M oscow, Russia, July 15-19, p. 76.

Milisenda C.C., Horikawa Y., Emori K., Miranda R., Bank F.H., Henn U. (2006) N eues Vorkommen kupferführender Turmaline in Mosambik [A new find of cuprian tourmalines in Mozambique]. Gemmologie: Zeitschrift der Deutschen Gemmologischen Gesellschaft, Vol. 55, N o. 1-2, pp. 5-24.

Mozambique Paraiba tourmaline hot in Tucson (2007) Jewellery News Asia, N o. 272 (A pril), p. 56.

Pearce N .J.G., Perkins W.T., Westgate J.A., Gorton M .P., Jackson S.E., N eal C.R., Chenery S.P. (1996) A pplication of new and published major and trace elements data for NIST SRM 610 and NIST SRM 612 glass reference materials. Geostandards Newsletter, Vol. 20, No. 2, pp. 115-144.

Petsch E.J. (1986) Riesen in Rot, Grün und Blau-Die TurmalinVorkommen in Mocambique. Mineralientage München 85Turmalin, Oct. 18-20, Munich, Germany.

Pinna P., Marteau P., Becq-Giraudon J.-F., M anigault B. (1986) Notice Explicative de la Carte Géologique à 1/1 000000 de la République Populaire du Mozambique (1986). BGRM, Orléans, France, 261 pp. (includes geologic map).

Pinna P., Jourde G., Calvez J.Y., M roz J.P., M arques J.M . (1993) The Mozambique Belt in northern Mozambique: Neo-proterozoic (1100-850 Ma) crustal growth and tectogenesis, and superimposed Pan-African (800-550 Ma) tectonism. Precambrian Research, Vol. 62, pp. 1-59.

Rondeau B., Delaunay A. (2007) Les tourmalines cuprifères du $\mathrm{Nigeria}$ et du Mozambique [Cuprian tourmalines from Nigeria and M ozambique]. Revue de Gemmologie, N o. 160, pp. 8-13.

Rossman G.R., Mattson, S.M. (1986) Yellow, Mn-rich el baite with $\mathrm{Mn}-\mathrm{Ti}$ interval ence charge transfer. American Mineral ogist, Vol. 71 , pp. 599-602.

Samson I., Anderson A., M arshall D. (2003) Fluid Inclusions, Analysis and Interpretation. Mineralogical Association of Canada Short Course Series, Vol. 32, 374 pp.

Shigley J.E., Cook B.C., Laurs B.M., Bernardes de Oliveira M . (2001) An update on "Paraíba" tourmaline from Brazil. Gems \& Gemology, Vol. 37, N o. 4, pp. 260-276.

Slater M. (2006) Globetrotter Travel Map - Mozambique, 3rd ed. N ew Holland (Publishers) Ltd., London, UK.

Smith C.P., Bosshart G., Schwarz D. (2001) Gem N ews International: Nigeria as a new source of copper-manganese-bearing tourmaline. Gems \& Gemology, Vol. 37, N o. 3, pp. 239-240.

Wentzell C.Y. (2004) Lab N otes: Copper-bearing color-change tourmaline from Mozambique. Gems \& Gemology, Vol. 40, No. 3, pp. 250-251.

Wentzell C.Y., Fritz E., Muhlmeister S. (2005) Lab N otes: M ore on copper-bearing color-change tourmal ine from M ozambique. Gems \& Gemology, Vol. 41, No. 2, pp. 173-175.

Wise R.W. (2007) M ozambique: The new Paraiba? Colored Stone, Vol. 20, No. 2, pp. 10-11. 